\title{
Mesoporous Carbon from Optimized Date Stone Hydrochar by Catalytic Hydrothermal Carbonization Using Response Surface Methodology: Application to Dyes Adsorption
}

\author{
Faiçal El Ouadrhiri (iD, ${ }^{1}$ Majda Elyemni (iD, ${ }^{2}$ Amal Lahkimi (iD, ${ }^{1}$ Abdelhadi Lhassani, \\ Mehdi Chaouch, ${ }^{4}$ and Mustapha Taleb ${ }^{1}$ \\ ${ }^{1}$ Laboratory of Engineering, Molecular Organometallic Materials and Environment, Faculty of Sciences Dhar El Mehraz, \\ Sidi Mohamed Ben Abdellah University, Fez, Morocco \\ ${ }^{2}$ Laboratory of Biotechnology, Faculty of Sciences Dhar El Mehraz, Sidi Mohamed Ben Abdellah University, Fez, Morocco \\ ${ }^{3}$ Laboratory of Processes, Materials and Environment, Faculty of Sciences and Technology, \\ Sidi Mohamed Ben Abdellah University, Fez, Morocco \\ ${ }^{4}$ Laboratory of Materials Engineering and Environment, Faculty of Sciences Dhar El Mahraz, \\ Sidi Mohammed Ben Abdelah University, Fez, Morocco
}

Correspondence should be addressed to Faiçal El Ouadrhiri; faical.elouadrhiri@usmba.ac.ma

Received 29 January 2021; Revised 27 March 2021; Accepted 2 April 2021; Published 22 April 2021

Academic Editor: Mohamed Zbair

Copyright (c) 2021 Faiçal El Ouadrhiri et al. This is an open access article distributed under the Creative Commons Attribution License, which permits unrestricted use, distribution, and reproduction in any medium, provided the original work is properly cited.

\begin{abstract}
Providing efficient and environmental friendly ways to recover lignocellulosic waste remains a challenge around the world. In this study, citric acid-catalyzed hydrothermal carbonization (CHTC) was coupled with pyrolysis to convert date seed (Ds) into adsorbent material. In this regard, a central composite design (CCD) using response surface methodology (RSM) was developed to examine the influence of temperature, reaction time, and catalyst dose on the mass yield $\left(Y_{\mathrm{m}}(\%)\right)$ and carbon retention rate $\left(\mathrm{C}_{\mathrm{RR}}(\%)\right)$ in the produced hydrochars. The optimized hydrochar $(\mathrm{OHC}-\mathrm{Ds})$ was obtained under optimal conditions $\left(200^{\circ} \mathrm{C}\right.$, $120 \mathrm{~min}, 20 \mathrm{mg}$ ) and characterized by a $Y_{\mathrm{m}}(\%)$ and $\mathrm{C}_{\mathrm{RR}}(\%)$ of $59.71 \%$ and $75.84 \%$, respectively. Chemical activation by $\mathrm{KOH}$ of OHC-Ds followed by pyrolysis at $600^{\circ} \mathrm{C}$ resulted in an active material (AOHC-Ds) rich in carbon and characterized by a high specific surface area of $1251.5 \mathrm{~m}^{2} / \mathrm{g}$, with the dominance of mesopores, as well as an amorphous structure comparable to graphite shown by X-ray diffraction (XRD) analysis. Adsorption experiments of two dyes on AOHC-Ds showed a high maximum adsorption capacity $\left(Q_{\mathrm{m}}\right)$ of $657.89 \mathrm{mg} \mathrm{g}^{-1}$ for methylene blue $(\mathrm{MB})$ and $384.61 \mathrm{mg} \mathrm{g}^{-1}$ for methyl orange (MO) compared to other conventional adsorbents. This result is due to the low acidity $\left(\mathrm{pH}_{\mathrm{pzc}}\right)$ of the surface of AOHC-Ds, which equals 6.75 , and its surface, which is also rich in oxygenated functional groups such as $(-\mathrm{OH}),(\mathrm{C}=\mathrm{O})$, and $(\mathrm{C}-\mathrm{O})$ shown by FTIR analysis. These results suggest that the coupling of $\mathrm{CHTC}$ and $\mathrm{KOH}$ activation followed by pyrolysis is an encouraging way to prepare an efficient and inexpensive adsorbent to remove dyes in wastewater.
\end{abstract}

\section{Introduction}

An unprecedented challenge in the field of energy and the environment marks the beginning of the twenty-first century. With $81 \%$ of the worlds energy supply dependent on fossil fuels [1], problems of depletion or explosion costs are looming on the horizon. Besides, the use of fossil fuels contributes to the development of greenhouse gases, which, according to the majority of the scientific community, are responsible for many climate changes on a planetary scale [2]. According to the World Health Organization (WHO), it is estimated that soon $2 / 3$ of the population could live in a region with limited access to water [3]. In order to remedy this problem, one of the options being considered is the reuse of wastewater even after passing through a treatment plant, especially for agriculture, which is the sector that 
consumes the most water [3]. Therefore, the problem is twofold: to meet the growing need for water and try to preserve our environment. Indeed, several molecules and compounds are present in wastewater, namely, hydrocarbons, dyes, heavy metals, xenobiotic molecules (endocrine disruptors), and pesticides [4]. Some of them are carcinogenic and contribute to the degradation of the environment and human health [5]. In this sense, many technologies have been innovated to decontaminate the wastewater and reduce pollution. Among them, adsorption has aroused great interest, since it has a high contaminant removal capacity and broad adsorbent-adsorbate selectivity [6]. Among the various adsorbents used, activated carbon (AC) is the most used for these many properties [7]. The increasing demand for activated carbon leads to intensive research into renewable precursors' production, mainly biomass, for their production [8]. Biomass has many advantages, not only in terms of abundance and distribution but also in terms of its conversion/recovery using a wide range of technologies: thermal (direct combustion) to produce heat and electricity, as well as for the production of electricity [9], thermochemical (gasification, pyrolysis, and hydrothermal carbonization) [10], and biological (anaerobic digestion and fermentation), its simplicity of execution, the removal of energy-intensive drying processes, and greenhouse gas emissions reduction. In recent years, significant attention has been paid to hydrothermal carbonization (HTC) as a promising method of conversion that can recycle waste, lead to low-cost development of new porous materials, and respond to specific environmental challenges [11].

The world production of dates is still increasing. In Morocco, the annual production is around 160,000 tons of dates, making it in the 3rd place among the Maghreb countries and the 7th in the world [12]. Date seeds have several uses in various fields. For example, the use of the oil extracted from date seed in cosmetics and also the grounded seeds are used as an additive to coffee. In fact, a study [13] showed that the aqueous extract of date seeds has an antigenotoxic effect. Despite its uses, date seeds are still considered waste and thrown away either by consumers or industrialists without valorization. According to [14], date seeds contain about $57 \%$ cellulose, $23 \%$ hemicellulose, and $15 \%$ lignin [14]. This is why it is crucial to find a new and appropriate way to enhance the value of date seeds.

In the recent literature, several studies have been conducted to manufacture adsorbents from date seeds using classical production methods such as pyrolysis or gasification followed by chemical or physical activation or coupling between them [15]. To the best of our knowledge, no studies have shown the use of the catalyzed hydrothermal carbonization process (CHTC) using citric acid in the preparation of adsorbent materials from date seeds. However, activated carbon from date seeds via HTC coupled with chemical activation by $\mathrm{NaOH}$ has been reported by [16]. According to [17], the two parameters that have an important influence are the temperature and the reaction time as well as the $\mathrm{pH}$ of the reaction which is little studied in the literature. In this study, the preparation of a carbon-rich material from date seeds using citric acid-catalyzed hydrothermal carbonization and their dye adsorption application have been the innovative outlooks.

More specifically, the objectives of this study are

(i) The optimization of the CHTC operating parameters (temperature, reaction time, and catalyst dose) on mass yield $\left(Y_{\mathrm{m}}(\%)\right)$ and carbon retention rate $\left(\mathrm{C}_{\mathrm{RR}}(\%)\right)$ in hydrochar produced from date seeds using RSM coupled with CCD design

(ii) The preparation of the active material from the optimized hydrochar was prepared by the $\mathrm{KOH}$ impregnation method reported by [18] with modification

(iii) The evaluation of the capacity of the activated material (AOHC-Ds) on the adsorption of a cationic dye (methylene blue: $\mathrm{C}_{16} \mathrm{H}_{18} \mathrm{ClN}_{3} \mathrm{~S}$ ) and an anionic dye (methyl orange: $\mathrm{C}_{14} \mathrm{H}_{14} \mathrm{~N}_{3} \mathrm{NaO}_{3} \mathrm{~S}$ ), which represent the most dyes used in the industry [19]

This study, through the various techniques employed, such as elemental analysis (CHNO), surface chemistry (FTIR), porosity analysis, $\mathrm{X}$-ray diffraction (XRD), and $\mathrm{pH}$ at zero points of charge $\left(\mathrm{pH}_{\mathrm{pzc}}\right)$, has clearly shown that the integration of CHTC is an encouraging way to convert date seeds into a carbonaceous material that is highly efficient in the removal of dyes in water.

\section{Materials and Methods}

2.1. Collection and Preparation of Raw Material. The date seeds (Ds) chosen in this study as a precursor were obtained from the local market in Fez, Morocco. First, seeds were washed with distilled water (DW) and put in an oven at $65^{\circ} \mathrm{C}$ for 12 hours, ground in a $\mathrm{GM}_{200}$ grinder (Retsch, $\mathrm{GmbH}$, Germany), sieved to obtain a particle size fraction of $500 \mu \mathrm{m}<d<250 \mu \mathrm{m}(60-35 \mathrm{mesh})$ for better decomposition in the CHTC process, and finally stored in a desiccator for later use. $\mathrm{NaOH}$ and $\mathrm{HCl}$ used in this work are analytical grade. Citric acid was ACS reagent grade with a purity of $\geq 99.5 \%$ (Sigma-Aldrich, Inc.).

\subsection{Hydrothermal Carbonization (HTC)}

2.2.1. Synthesis of Hydrochars. The hydrothermal carbonization of date seeds was carried out in a polypropylene-lined (PPL) autoclave with a volume of $100 \mathrm{~mL}$. In each experiment, $8 \mathrm{~g}$ of the Ds powder was mixed with $80 \mathrm{~mL}$ of DW to have a biomass/water ratio of $1: 10$ with stirring for $10 \mathrm{~min}$. A precise mass between $10 \mathrm{mg}$ and $20 \mathrm{mg}$ of citric acid $\left(\mathrm{C}_{6} \mathrm{H}_{8} \mathrm{O}_{7}\right)$ as an acid catalyst was added to the mixture during stirring and then loaded into the reactor and well sealed. The autoclave was transferred to an oven and heated 
to the target temperature for a specific time (40-140 min). All experiments were carried out at a constant heating rate of $5^{\circ} \mathrm{C} / \mathrm{min}$. After the reaction, the autoclave was cooled naturally, and the hydrochar is recovered by centrifugation, washed with DW, dried at $105^{\circ} \mathrm{C}$ overnight, and stored. The hydrochar is named $\mathrm{HC}-\mathrm{ND}_{x}$ ( $x$, number of experiments).

2.2.2. Hydrochar Activation. The optimized hydrochar selected in the optimization part was chemically activated by the $\mathrm{KOH}$ impregnation method reported by $[18,20] .5 \mathrm{~g}$ of OHC-Ds were impregnated with $100 \mathrm{~mL}$ of $\mathrm{KOH}(2 \mathrm{M})$ solution for 4 hours at room temperature and continuous stirring and then dried in the oven at $60^{\circ} \mathrm{C}$ overnight. Finally, the powder obtained was sintered in a muffle furnace at $600^{\circ} \mathrm{C}$, for one hour. The final activated material named AOHC-Ds was washed with DW and dried in the oven overnight and then stored.

2.3. Design of the CCD/RSM. Design of experiments (Doe) and response surface methodology (RSM) are useful tools for studying, developing, and optimizing a wide range of engineering systems [21]. The Doe approach using RSM is a robust tool for understanding and optimizing experimental parameters, allowing a rational interpretation of their influence on the selected responses with a considerable reduction in the number of experiments and an improved understanding of the process mechanism [22]. In this work, the effect of temperature $\left(X_{1}\right)$, reaction time $\left(X_{2}\right)$, and catalyst dose $\left(X_{3}\right)$ on two responses, mass yield $\left(Y_{\mathrm{m}}(\%)\right)$ and carbon retention rate $\left(\mathrm{C}_{\mathrm{RR}}(\%)\right)$, has been described by a quadratic polynomial model using the following equation, including linear effects, interaction effects, and quadratic effects, i.e., for $k$ independent factors:

$$
Y_{i}=\beta_{0}+\sum_{i=1}^{n}\left(\beta_{i} X_{i}\right)+\sum_{i=1}^{n}\left(\beta_{i i} X_{i}^{2}\right)+\sum_{i=1}^{n-1} \sum_{j=1}^{n}\left(\beta_{i j} X_{i} X_{j}\right)+\mathscr{E},
$$

where $Y_{i}$ is the measured response to the experiment $i . \beta$ is the constant regression coefficient. $X_{j}$ and $X_{i}$ are the independent coded prediction variables called factors. $\mathscr{E}$ design the difference between the observed and estimated values of the measured response called total error.

Based on the central composite design (CCD) using Expert-Design software, which is one of the most used matrices due to its good performance and minimum number of experiments [23], 20 experiments were suggested for $k=3$ factors according to the following equation:

$$
N=2^{k}+2 \times k+N_{0}=2^{3}+2 \times 3+6=20 .
$$

Include $\left(2^{k}=8\right)$ experiments corresponding to the factorial design $(2 k=6)$ experiments located on the axes and $\left(N_{0}=6\right)$ experiments at the center of the domain. The latter was chosen equal to six to determine the experimental error and ensure the accuracy and reliability of our model at any point of the experimental domain. In order to account for any randomized hidden effects, the experiments were conducted in the random order (Table 1S). Figure 1S shows the geometric location of the experimental points of the CCD design. The levels used $-\alpha,-1.0,+1$, and $+\alpha$ for the three variables in the CCD design of which $\alpha=(2 k)^{1 / 4}=1.682$ to ensure the isovariance property by rotation of the design, as presented in Table 1.

Once the modeling is complete, the final step of the study is optimization, which consists of finding the response functions optimal levels. Several optimization methods can be used to simultaneously optimize the two studied responses resulting from the use of the response surface method. In this study, the numerical method was applied using the desirability function $(D)$. This methods choice is taken because it gives us the possibility to modify the weight and importance either for the variables or the responses. Besides, all these criteria were combined in a single desirability function $(D)$ [24]. The software allows us to estimate the predicted values by the value of $D$ varying from 0 to 1 with perfect values when $d=1$ [25].

2.4. Characterization. The elemental analysis of carbon (C), hydrogen $(\mathrm{H})$, nitrogen $(\mathrm{N})$, and sulfur $(\mathrm{S})$ was carried out in an apparatus (2400 CHN Elemental Analyzer, Perkin-Elmer, France), and the percentage of oxygen was calculated by subtraction. The prediction of the higher heat value (HHV) was made using the unified model (equation (3)) developed by [26], which is based on elemental analysis and which involved more variables in the prediction of the calorific values of our samples $[27,28]$. The $Y_{\mathrm{m}}(\%)$ and $\mathrm{C}_{\mathrm{RR}}(\%)$ are the two responses studied in order to optimize them. The $Y_{\mathrm{m}}(\%)$ was calculated by equation (4) according to $[29,30]$. $\mathrm{C}_{\mathrm{RR}}(\%)$ is defined as the fraction of carbon in the hydrochar (\% $\mathrm{C}_{\text {hydrochar }}$ ) to that of the initial biomass ( $\% \mathrm{C}_{\text {raw biomass }}$ ). This response was calculated using equation (5) as ratios by $[31,32]$

$$
\begin{aligned}
\operatorname{HHV}\left(\frac{\mathrm{MJ}}{\mathrm{Kg}}\right) & =32.7934+0.0053(\mathrm{C})^{2}-0.5321(\mathrm{C})-2.8769(\mathrm{H})+0.0608(\mathrm{C} \times \mathrm{H})-0.2401(\mathrm{~N}), \\
Y_{m}(\%) & =\frac{\text { Mass of dry hydrochar }(\mathrm{g})}{\text { Mass of dry raw biomass }(\mathrm{g})} \times 100, \\
\mathrm{C}_{\mathrm{RR}}(\%) & =\frac{\text { quantité de carbon dans le dry hydrochar }}{\text { quantité de carbon dans le dry raw biomass }}=\frac{\% \mathrm{C}_{\text {hydrochar }}}{\% \mathrm{C}_{\text {raw biomass }}} \times Y_{m}(\%) \times 100 .
\end{aligned}
$$


TABLE 1: Factors and their levels of the central composite design (CCD).

\begin{tabular}{lccccccc}
\hline Variable name & Code & $-1.68(-\alpha)$ & $+1.68(+\alpha)$ & Coded low & Coded high & Mean & Std. deviation \\
\hline$A=$ temperature $\left({ }^{\circ} \mathrm{C}\right)$ & $X_{1}$ & 166.36 & 233 & $-1 \leftrightarrow 180.00$ & $+1 \leftrightarrow 220.00$ & 200.00 \\
$B=$ reaction time $(\mathrm{min})$ & $X_{2}$ & 40 & 140 & $-1 \leftrightarrow 60.00$ & $+1 \leftrightarrow 120.00$ & 90.00 & 25.43 \\
$C=$ catalyst dose $(\mathrm{mg})$ & $X_{3}$ & 13.30 & 21.70 & $-1 \leftrightarrow 15.00$ & $+1 \leftrightarrow 20.00$ & 17.50 & 2.12 \\
\hline
\end{tabular}

The textural characteristics of OHC-Ds and AOHC-Ds were determined by the isotherms of nitrogen physisorption at $77.35 \mathrm{~K}$ using an ASAP 2020 manometric analyzer (Micromeritics, USA). The specific surface area was calculated by the Brunauer-Emmett-Teller (BET) method in the range of $0.05-0.35$. The total pore volume $V_{p}$ was obtained from the amount of absorbed nitrogen at $P / P_{0} \approx 0.99$. The micropore volume $V_{\text {micro }}$ was calculated using the $t$-plot method with the thickness $t$ which equals $t=\left(P / P_{0}\right)^{2}+6.45\left(P / P_{0}\right)+2.98 \AA$ specific for carbon-based materials [33]. The mesoporous volume $V_{\text {meso }}$ was deduced by subtraction $V_{\text {méso }}=V_{\text {micro }}-V_{p}$. The pore size distribution was determined by the Barrett-Joyner-Halenda (BJH) method [34]. Besides, the pores average diameter $\left(D_{p}\right)$ was calculated by assimilating them to a cylindrical shape $D_{p}=$ $4 \times V_{p} / S_{\mathrm{BET}}$ [35]. The functional groups of the raw biomass surface, carbon material, and changes due to the HTC process were demonstrated by a Fourier transform infrared spectroscopy (FTIR) (Perkin Elmer, USA). Samples for measurements were prepared using the $\mathrm{KBr}$ disc method in the range $500-4000 \mathrm{~cm}^{-1}$. The identification of the crystalline phases (position and intensity of the diffracted lines) was carried out by X-ray diffraction (XRD) using a Bruker $D$ Discover diffractometer (Germany), equipped with $\mathrm{Cu}-\mathrm{K} \alpha$ radiation $\left(1.54 \AA\right.$ ), covering an angular range from $5^{\circ}$ to $50^{\circ}$ with a step of $0.05^{\circ}$. The $\mathrm{pH}_{\mathrm{pzc}}$ (zero charge point) is defined as the $\mathrm{pH}$ value when the materials surface charge is zero. The $\mathrm{pH}_{\mathrm{pzc}}$ of the AOHC-Ds was determined by the $\mathrm{pH}$ drift method described in supporting information (SI), the most accurate method according to $[36,37]$.

2.5. $M B$ and $M O$ Adsorption Test onto AOHC-Ds. AOHC-Ds were used as an adsorbent for the removal of methyl orange and methylene blue from water. The effect of $\mathrm{pH}$ on $\mathrm{MB}$ and $\mathrm{MO}$ removal rate through $\mathrm{AOHC}-\mathrm{Ds}$ was achieved in the range $2-12$. The solution $\mathrm{pH}$ was adjusted either by the addition of $\mathrm{HCl}(0.1 \mathrm{M})$ or $\mathrm{NaOH}(0.1 \mathrm{M})$. The influence of the AOHC-Ds dose in the range 2.5-25 mg, the initial concentration of $\mathrm{MB}$ and $\mathrm{MO}$ in the range 25-900 $\mathrm{mg} \mathrm{L}^{-1}$, and the contact time in the range 0-60 min were performed in batches in $100 \mathrm{~mL}$ volumetric flasks under constant magnetic agitation. After each test, the supernatants' concentration was determined using a UVvisible spectrophotometer at wavelength $465 \mathrm{~nm}$ for $\mathrm{MO}$ and $664 \mathrm{~nm}$ for MB. By preparing $\mathrm{MB}$ and $\mathrm{MO}$ concentrations from $0 \mathrm{mg} \mathrm{L}^{-1}$ to $10 \mathrm{mg} \mathrm{L}^{-1}$, from a stock solution of concentration $1 \mathrm{~g} \cdot \mathrm{L}^{-1}\left(C_{\text {stock }}=1 \mathrm{~g} \cdot \mathrm{L}^{-1}\right)$, a calibration curve was made with a coefficient $R_{(\mathrm{MB})}^{2}=0.999$ and $R_{(\mathrm{MO})}^{2}=0.998$. The equations applied for the calculation of the adsorption removal rate $R \%$, the adsorption capacity $Q_{e}$, as well as the two adsorption models used in this work are presented in Table 6S.

\section{Results and Discussion}

3.1. Modeling and Analysis of the Statistical Properties of the CHTC Process. In this study, RSM coupled with the CCD plan was used to describe the variation in interest responses as a function of factor fluctuations and determine the factors involved in achieving the original objectives. The quality assessment of each model was tested using the analysis of variance (ANOVA) by the Fishers test ( $F$ value), the probability $p$ ( $P$ value), and the significance of the lack of fit to determine whether the model correctly summarizes the results of the design of experiment tests [21]. The regression models fit the evaluation of its predictive qualities, and its operation was verified using the correlation coefficient of the multilinear regression ( $R$-squared), helpful in describing the variation in the experimental data that the model explains. This coefficient can be misleading for evaluating the fit of the model predicted. For this reason, the coefficient adjusted $R_{\text {adjusted }}^{2}$ and the coefficient predicted $R_{\text {predicted }}^{2}$ were introduced into the evaluation to determine the model's ability to predict new observations. In addition, normal residual and predicted versus normal value plots were used to assess the residuals distribution and normality.

3.1.1. Model $Y_{m}(\%)$. The experimental values of the CCD matrix of mass yield experiments presented in Table $1 S$ allowed the mathematical model to be adjusted by the leastsquares procedure. The analysis of variance ANOVA in Table $2 \mathrm{~S}$ shows that the mass yield regression is very significant with an $F$ value of 349.33 and $P$ value $<0.0001$, on the one hand, and on the other hand, the lack of fit ( $F$ value of 2.09) is not statistically significant compared to the pure error. Moreover, the $R^{2}$ coefficient of the predicted model is 0.9968, which affirms the correlation and good fit between the experimental and calculated data. This is also confirmed by the difference between the $R_{\text {adjusted }}^{2}(0.9940)$ and the $R_{\text {predicted }}^{2}(0.9818)$, which is reasonable given that it is less than 0.2 . The coefficient of variance $(\mathrm{CV} \%)$ for $Y_{\mathrm{m}}(\%)$ is $0.65 \%$, which indicates that the model is capable of better prediction. The ANOVA analysis for the coded terms shows that only the temperature $\left(X_{A}\right)$, the term of the interaction $\left(X_{A} \times X_{B}\right)$, and the quadratic term of the catalyst dose $\left(X_{C}^{2}\right)$ have a significant influence on hydrochar mass yield given that their $P$ value is less than 0.05 . In addition, $P$ values of other terms greater than 0.1 reveal that these terms are statistically insignificant. Consequently, only the effects of the significant terms were considered in the following 
equation in terms of factors coded to predict mass yield values, namely,

$$
\begin{aligned}
Y_{\mathrm{m}}(\%)= & 58.86-5.79 \times\left(X_{A}\right)-0.24 \times\left(X_{A} \times X_{B}\right) \\
& -0.293 \times\left(X_{C}^{2}\right) .
\end{aligned}
$$

Indeed, the terms ()$,\left(X_{A} \times X_{B}\right)$, and $\left(X_{C}^{2}\right)$ have quite a negative effect on the mass yield with a negative coefficient of $-5.79,-0.24$, and -0.29 , respectively. In the same context, the normal plot of the residuals shown in Figure 1(a) indicates that the residue points distribution correctly follows the straight line, which justifies that the distribution is homogeneous. Besides, the importance of the experimental values was verified by plotting the predicted vs. actual plot. Figure 1(b) shows that the set of values was distributed close together around the diagonal line, which affirms the predicted model's accuracy and validity. The 3D response surface graphs obtained from equation (6) for the mass yield are shown in Figure 2S, showing that there is a wide range of variables for which the mass yield is almost flat in the range $160^{\circ} \mathrm{C}<T<240^{\circ} \mathrm{C}, 32 \mathrm{~min}<t<120 \mathrm{~min}$ for a fixed catalyst dose equal to $17.5 \mathrm{mg}$. For example, the mass yield in hydrochar increased from $67.9 \%$ to $49.2 \%$ by varying the temperature from $165^{\circ} \mathrm{C}$ to $235^{\circ} \mathrm{C}$. In general, for $X_{A}-X_{B}$ values, an increase in these two variables leads to a slight decrease in the hydrochar $Y_{\mathrm{m}}(\%)$. Our results are in agreement with those reported on hydrothermal carbonization of biomass [38-40].

These results can be explained by the dehydration, condensation, polymerization, and aromatization reactions during hydrothermal processing of the cellulose and hemicellulose contained in the biomass matrix [41, 42]. In addition, the hydrochar mass yield by the HTC process in the case of the date seed is much higher with biomass conversion techniques such as pyrolysis $[43,44]$ and gasification. On the other hand, the $2 \mathrm{D}$ and $3 \mathrm{D}$ graphs in Figures $1(\mathrm{c})$ and $1(\mathrm{~d})$ show that the temperature increase and the catalyst dose $\left(X_{C}\right)$ in the range $160^{\circ} \mathrm{C}<X_{T}<240^{\circ} \mathrm{C}$, $14 \mathrm{mg}<X_{C}<21 \mathrm{mg}$ for a fixed time of $120 \mathrm{~min}$ have a negative and little noticeable effect on the mass yield of hydrochar. It is concluded that while temperature and time play the leading role in the HTC process, the mass yield decreased as the dose of citric acid increased. Our results are very similar to [45], to maize silage [39], and to salacca peel and not in the case of resin pulp [46].

3.1.2. Model $C_{R R}(\%)$. The carbon recovery rate is defined as the amount of carbon in the hydrochar relative to the amount of carbon in the biomass [32]. The RSM was used to determine the relationship between $\mathrm{C}_{\mathrm{RR}}(\%)$ and the three variables studied. The ANOVA analysis is presented in Table 3S. As we can see, on the one hand, the $R_{\text {Predicted }}^{2}$ coefficient of 0.8561 is in reasonable agreement with $R_{\text {adjusted }}^{2}$ (0.9541). On the other hand, the $R^{2}$ coefficient is 0.9759 , indicating the model's excellent fit to the experimental data. Moreover, compared to the pure error, the $F$ value of the lack of fit is 2.48, which means that the lack of fit is not important, with a $\mathrm{CV} \%$ of 0.98 , which shows that the model explains well the totality of the experimental data. Indeed, from the $P$ value values of the coded terms, we can conclude that temperature $\left(X_{A}\right)$, time $\left(X_{B}\right)$, the dose of citric acid $\left(X_{C}\right)$, and the quadratic terms $\left(X_{A}^{2}\right)$ and $\left(X_{B}^{2}\right)$ are the only terms statistically significant for $\mathrm{C}_{\mathrm{RR}}(\%)$. Then, the final equation (equation (7)) of the quadratic model for the carbon recovery rate in terms of the coded variables is

$$
\begin{aligned}
\mathrm{C}_{\mathrm{RR}}(\%)= & 75.79-3.45 \times X_{A}+1.07 \times X_{B}+0.53 \times X_{C} \\
& -1.4 \times X_{A}^{2}-0.6 \times X_{B}^{2} .
\end{aligned}
$$

Regarding the validity and correctness of the model, it can be seen that not only the distribution of the points around the straight line in the normal plot (Figure 2(a)) is homogeneous but also the actual values were distributed evenly from the diagonal in the predicted vs. actual plot (Figure 2(b)). The relationship between the variables (temperature, time, and nitric acid dose) was established using equation (7) via the $3 \mathrm{D}$ and $2 \mathrm{D}$ response surface plots. The plots parabolic shape in Figures 2(c) and 2(d) shows the influence of temperature and time on the carbon recovery rate. As can be seen, the optimum operating point of the process, located within the experimental range of the studied variables, corresponds to the cones stationary point. For example, passing from a temperature of $150-230^{\circ} \mathrm{C}$ for a fixed reaction time $(120 \mathrm{~min})$, we observe the passage of $\mathrm{C}_{\mathrm{RR}}(\%)$ through an optimum region hatched in red. These findings are consistent with those of $[38,47,48]$. However, Figure $3 \mathrm{~S}$ shows that at lower temperatures $\left(180-200^{\circ} \mathrm{C}\right)$, we find that $\mathrm{C}_{\mathrm{RR}}(\%)$ increases with increasing dose of citric acid, which is consistent with the conclusions of the study [49], in the case of pure cellulose. The only possible reason for these conclusions is that the CHTC process increases $\mathrm{C}_{\mathrm{RR}}(\%)$ in hydrochars and the citric acid that penetrates in the biomass matrix and thus causes the hydrolysis of cellulose, hemicellulose, and lignin. Indeed, the carbon contained in the citric acid can be adsorbed in the surface of the hydrochars, according to the study of [50], which makes the hydrochar much rich in carbon during catalyzed hydrothermal carbonization.

\subsection{Numerical Optimization of the HTC Process Using the} Desirability Function. Among the objectives of this study is developing a hydrochar from date seeds with controlled properties, particularly a carbon recovery rate and mass yield, which must be as high as possible. Using RSM/CCD, we have established the relationship between the process variables and the interest responses via the validated mathematical model and response surface graphs. However, the present study used the desirability function to determine the optimal level of carbon recovery rate in hydrochar with the constraints cited in Table 4S. Among the 27 solutions calculated by the software, function $D$ highest value is chosen as the optimal solution. Figure $4 \mathrm{~S}$ shows the variation of the highest desirability function $(88.70 \%)$ corresponding to the values $\left(X_{A}=200^{\circ} \mathrm{C}, X_{B}=120 \mathrm{~min}\right.$, and $\left.X_{C}=20 \mathrm{mg}\right)$. 


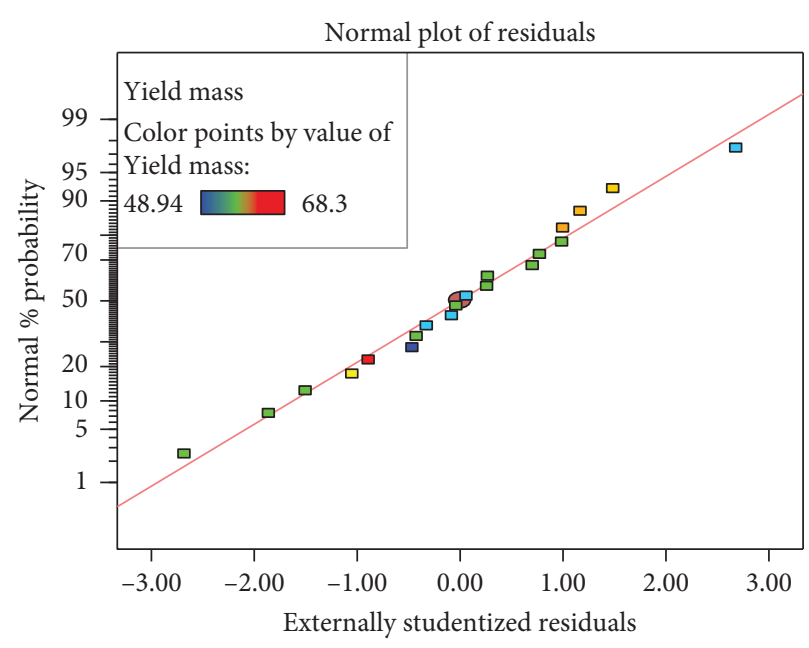

(a)

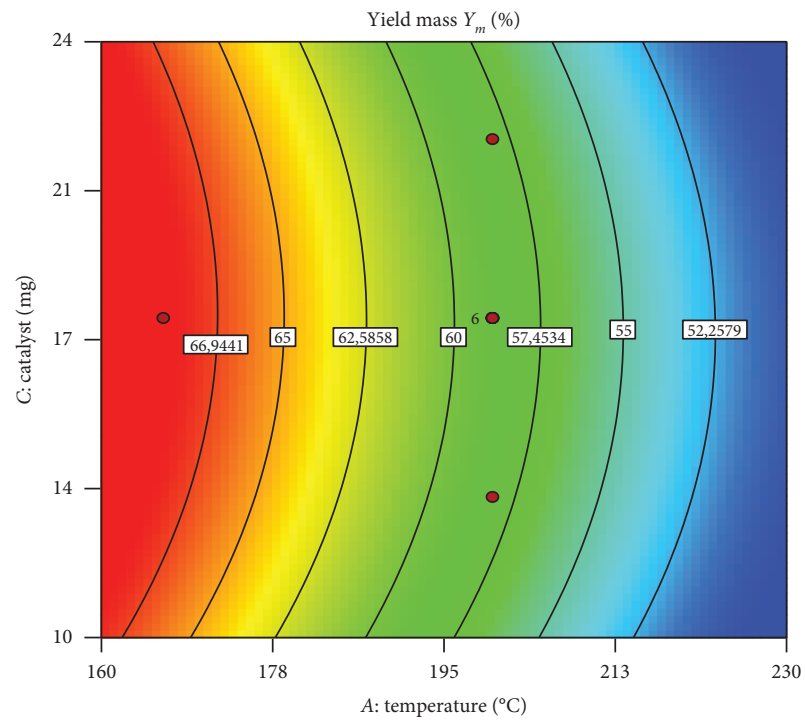

(c)

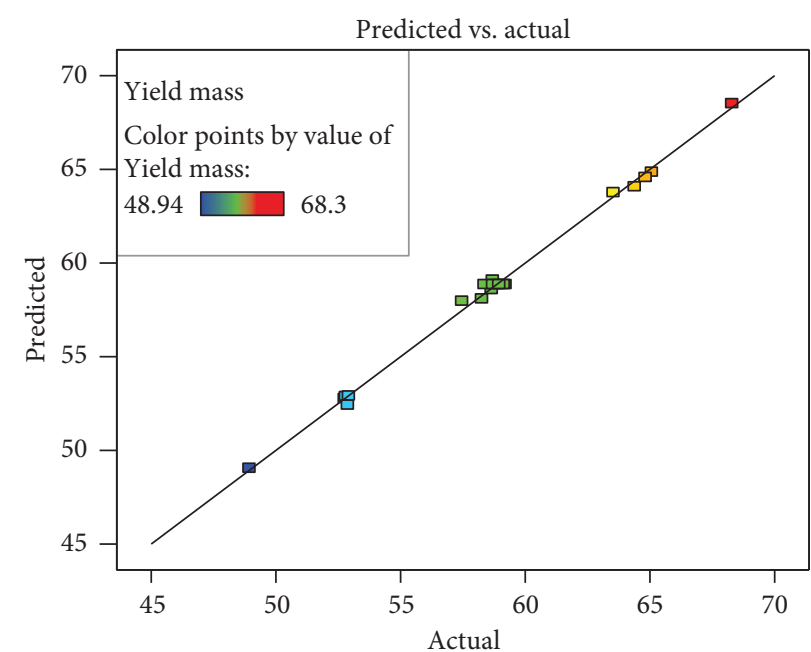

(b)

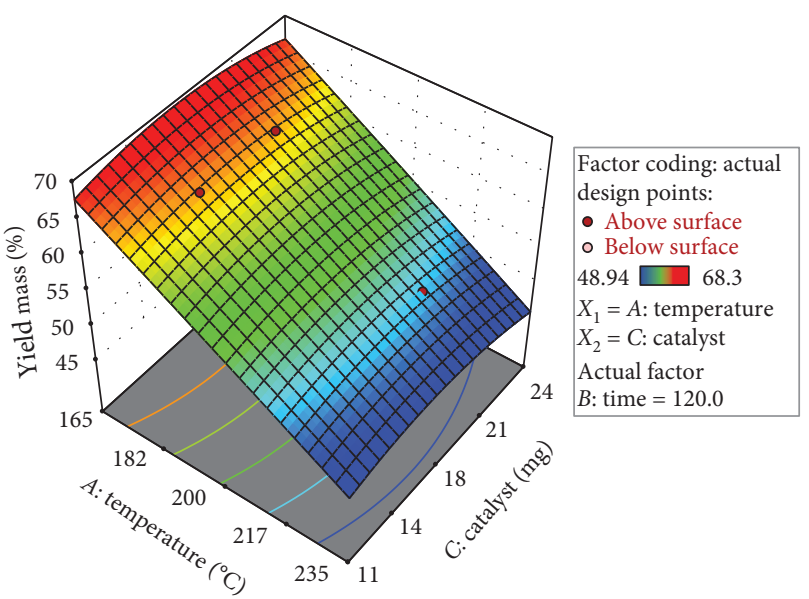

(d)

Figure 1: (a) Normal probability plot of the residual. (b) Predicted versus actual plot. ((c), (d)) Response surface of $Y_{\mathrm{m}}(\%)$ as a function of the temperature and of the dose of catalyst at $X_{B}=120 \mathrm{~min}$.

Under these conditions, the experiments presented in Table 2 show a carbon recovery rate of $74.84 \%$ and a mass efficiency of $60.1 \%$ with a percentage error of $2 \%$ and $1.7 \%$, respectively. It means that both models predicted using RSM/CCD reasonably follow the experimental data. Finally, the hydrochar-optimized OHC-Ds under the conditions $X_{A}=200^{\circ} \mathrm{C}, X_{B}=120 \mathrm{~min}$, and $X_{C}=20 \mathrm{mg}$ suffered chemical activation as detailed in the hardware and method section.

\subsection{Characterization of Hydrochars}

3.3.1. CHNO Analysis. The elemental analysis presented in Table 5S indicates that the percentage of carbon increased significantly during the HTC process with a maximum of $69.03 \%$ for $\mathrm{HC}-\mathrm{ND}_{17}$, which has a positive effect on the textural and adsorption properties of AOHC-Ds after chemical activation, according to [51]. On the other hand, the percentage of oxygen decreased by about $60 \%$ due to dehydration and decarboxylation reactions. These findings are consistent with the conclusions of [52], which used strong acids $\left(\mathrm{HCl}, \mathrm{H}_{2} \mathrm{SO}_{4}\right.$, and $\mathrm{HNO}_{3}$ ) to convert bamboo Moso into hydrochar using HTC. The atomic $\mathrm{O} / \mathrm{C}$ and $\mathrm{H} / \mathrm{C}$ ratios of the hydrochar and raw biomass were calculated using the elemental analysis and presented using the van Krevelen diagram [53] for purposes of comparison with other materials and to get an idea of the degree of carbonization.

As shown in Figure 3, the position of the hydrochars is between lignite, bituminous coal, and charcoal at the bottom and cellulose and wood at the top. It can also be seen that the atomic ratios follow a diagonal line, which indicates that the predominant reaction in the conversion of date seed to hydrochar using citric acid-catalyzed HTC is dehydration and decarboxylation. It is also noted that by increasing the temperature from $200^{\circ} \mathrm{C}$ to $233^{\circ} \mathrm{C}$, the conversion is characterized by a demethanization reaction, thus revealing the 


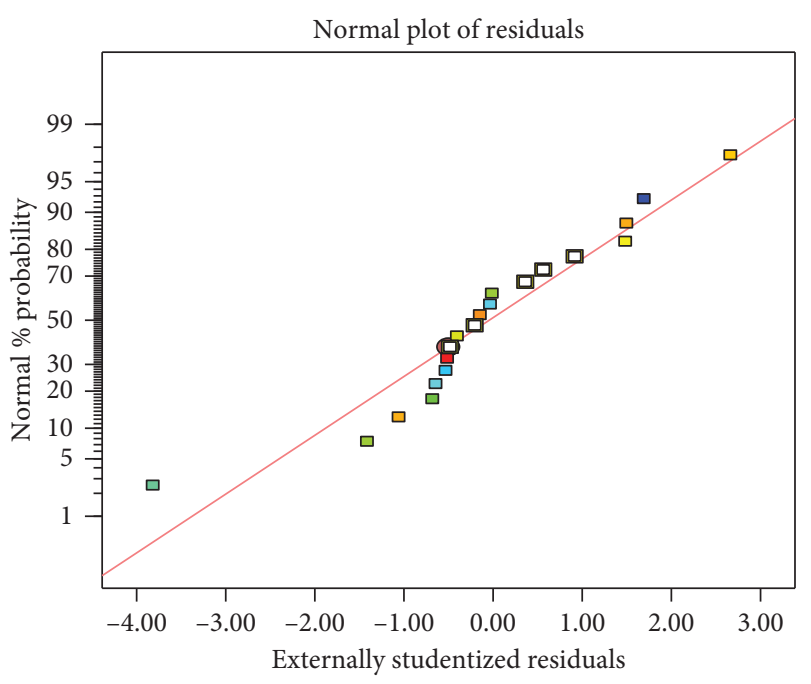

(a)

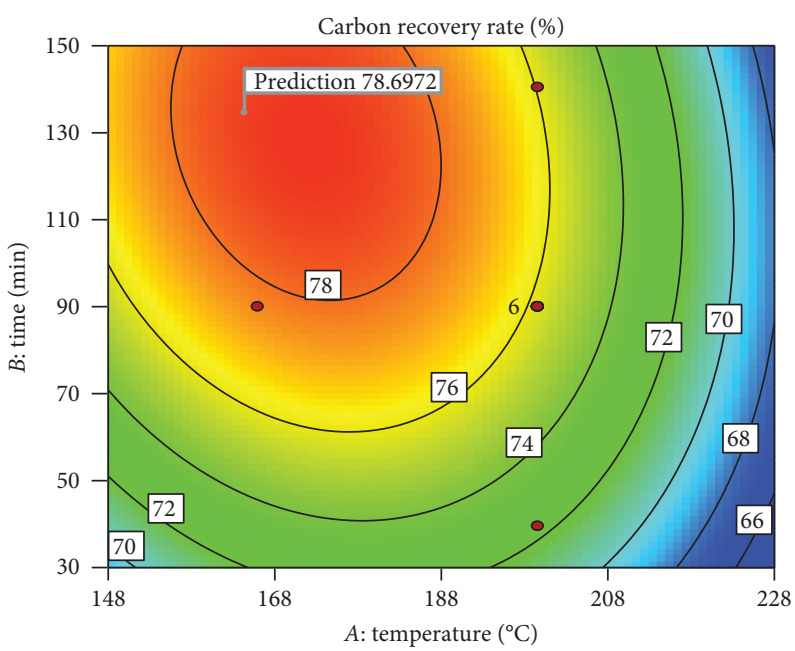

(c)

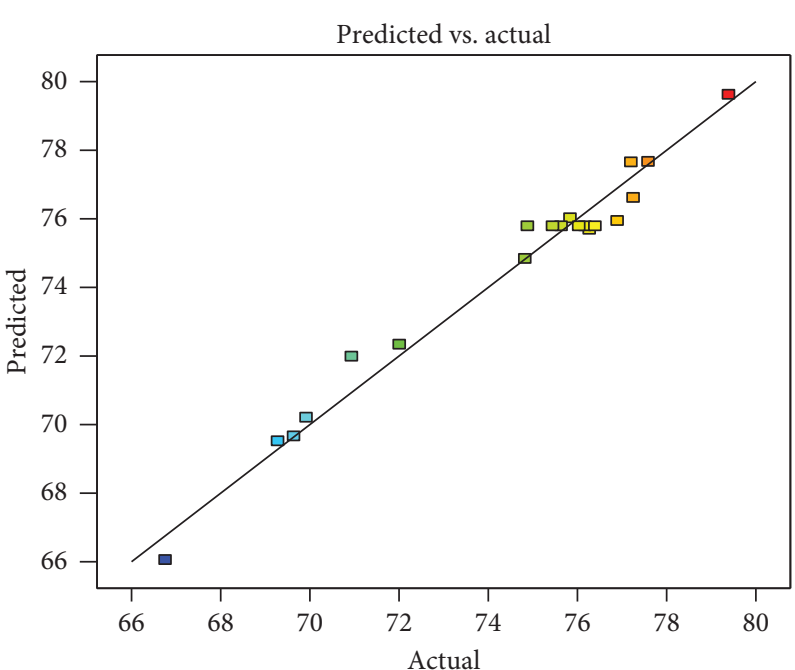

(b)

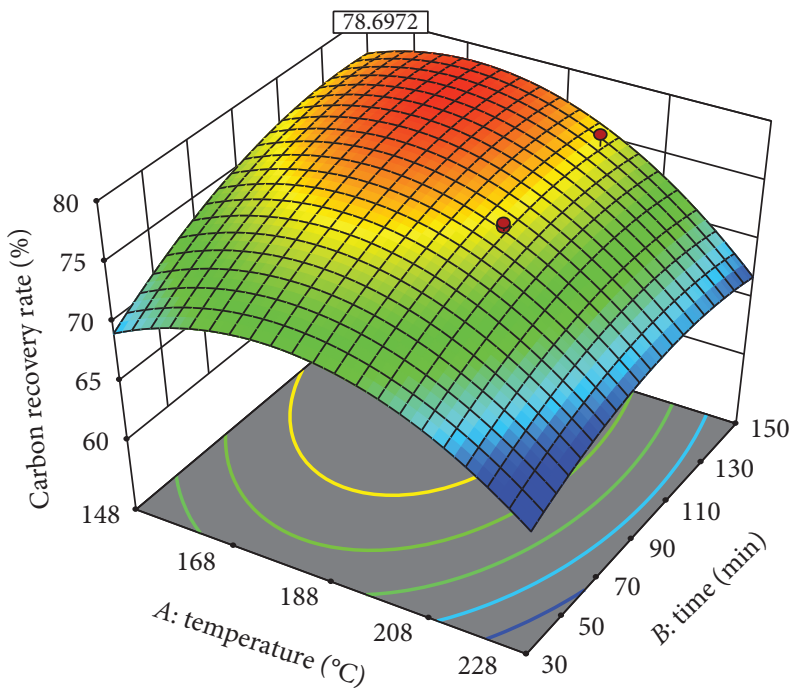

(d)

Figure 2: (a) Normal probability plot of the residual. (b) Predicted versus actual plot. ((c), (d)) Response surface of $\mathrm{C}_{\mathrm{RR}}(\%)$ as a function of temperature and time at $X_{c}=17.5 \mathrm{mg}$.

effect of citric acid in the formation of hydrochars, which is in agreement with the study of [52]. Another interesting remark is that the energy power represented by the higher heating value (HHV) of all samples was increased by about $70 \%$, which is interesting from an energy point of view. The results of this study for HHV are almost the same as several studies [54], in the case of grape marc [55], in the case of woody biomass, and for macrophyte Hornwort [56], who showed that the catalyzed HTC process had a direct positive effect on the energetic properties of hydrochars, whether it be the nature of the raw material or the operating conditions.

3.3.2. Porosity and Pore Size Distribution. The adsorptiondesorption isotherm of liquid nitrogen at $77 \mathrm{~K}$ of AOHC-Ds and OHC-Ds is shown in Figure 4. The isotherm of AOHC-Ds
TABle 2: Verification experiments under optimal conditions.

\begin{tabular}{|c|c|c|c|}
\hline \multicolumn{4}{|c|}{$\begin{array}{c}X_{A}=200^{\circ} \mathrm{C}, X_{B}=120 \mathrm{~min} \text {, and } X_{C}=20 \mathrm{mg} \text { (desirability } \\
\text { function }=88.70 \%)\end{array}$} \\
\hline & Predicted & Experimental & Error \\
\hline & 58.53 & 59.71 & $1.18(2 \%)^{*}$ \\
\hline $\mathrm{C}_{\mathrm{RR}} \%$ & 77.19 & 75.84 & $1.35(1.7 \%)^{*}$ \\
\hline
\end{tabular}

${ }^{*}$ Percentage error between experimental and model-predicted values.

is type IV typical of mesoporous materials [57]. According to the IUPAC classification, a hysteresis loop type $\mathrm{H} 4$ accompanies the presence of capillary condensation in the partial pressure region $(0.45-0.99)$ on its desorption branch [58]. This result indicates that AOHC-Ds is characterized by a porous structure with the dominance of mesopores $(2-50 \mathrm{~nm})$ and also including pores in the microporous region $(<2 \mathrm{~nm})$. The textural characteristics 


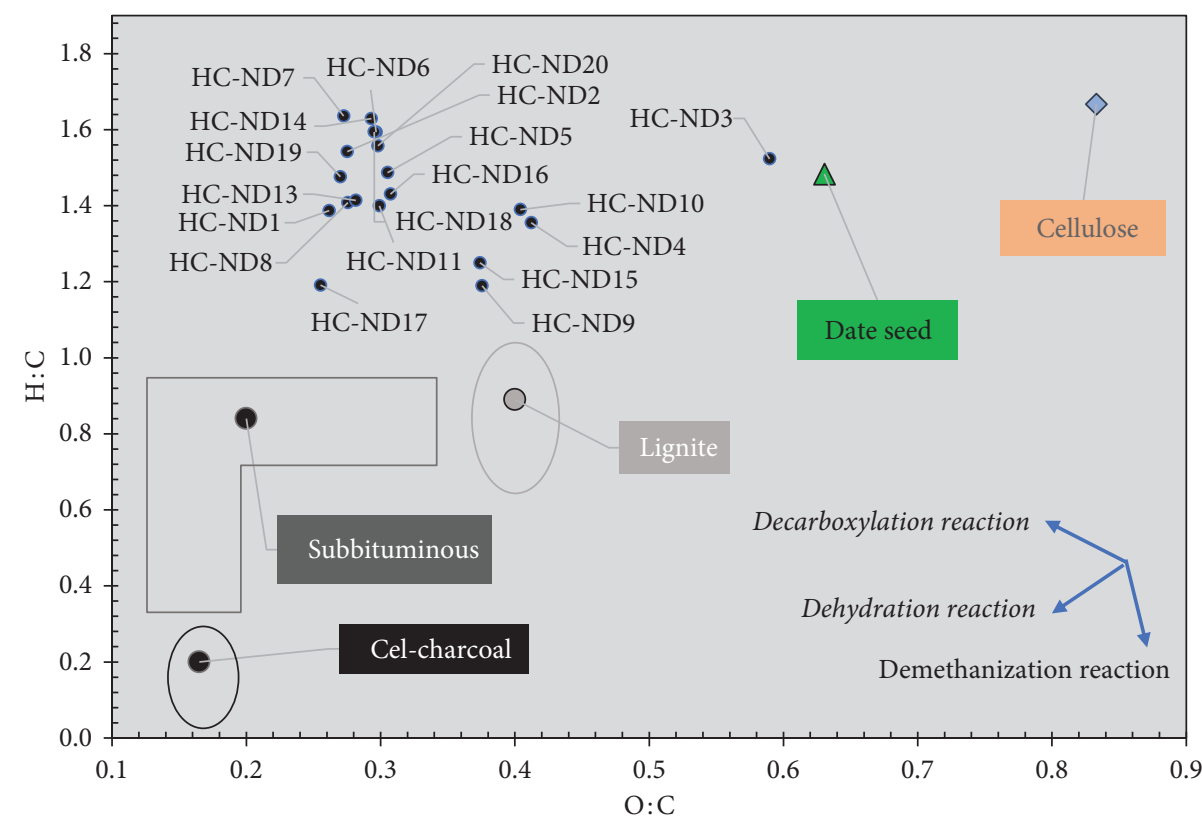

Figure 3: Van Krevelen diagram for all hydrochars produced from date seeds using the CCD.

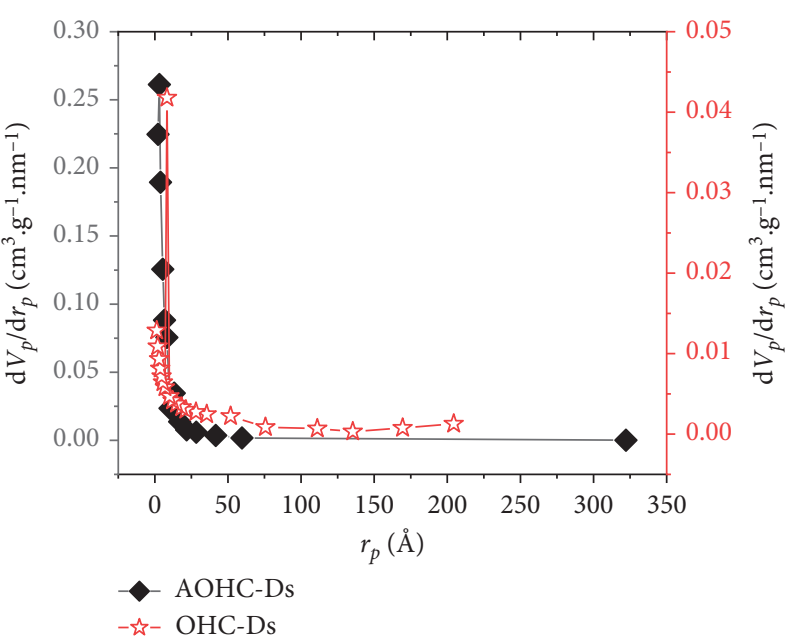

(a)

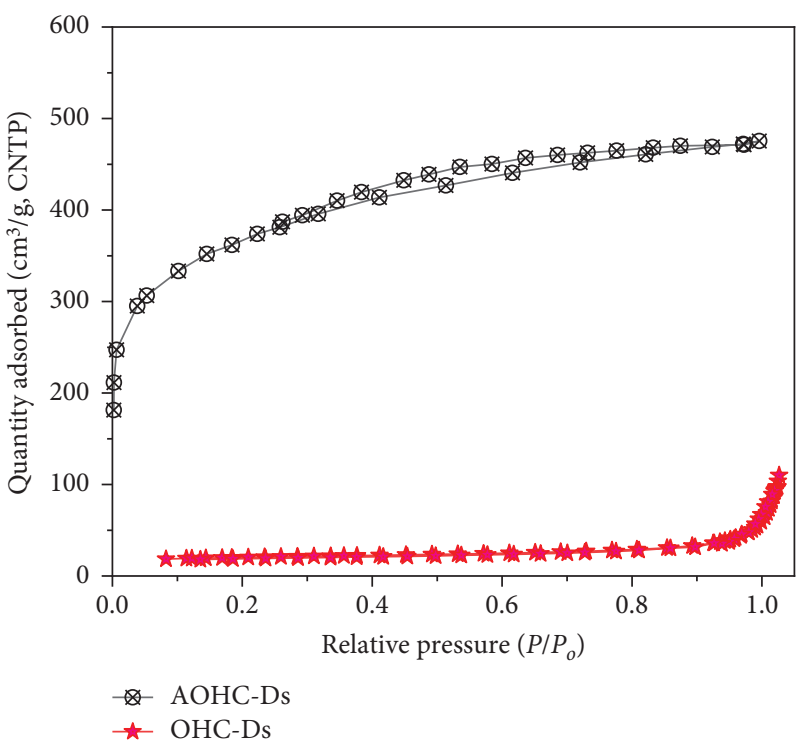

(b)

Figure 4: (a) Adsorption-desorption isotherm. (b) Pore size distribution of AOHC-Ds and OHC-Ds.

of the optimized hydrochar and activated hydrochar are presented in Table 3.

The hydrochar optimized under the conditions $X_{A}=200^{\circ} \mathrm{C}, X_{B}=120 \mathrm{~min}$, and $X_{C}=20 \mathrm{mg}$ is characterized by a BET surface area of $60.75 \mathrm{~m}^{2} / \mathrm{g}$ and a pore volume of $0.14 \mathrm{~cm}^{3} / \mathrm{g}$. These results are similar to the results of [59] in the case of hazelnut shell and a little high compared to those reported by $[39,60]$ in the case of residues from the wine industry and salacca peel, respectively. This finding can be explained by the type of raw material and the conditions of synthesis, including the introduction of citric acid as a catalyst in the hydrothermal reaction. Indeed, our results are in agreement with those reported by [39, 40, 59], which showed the positive effect of acidic conditions in the hydrothermal reaction on the porous structure of the hydrochar. In contrast, the pore size distribution by the BJH method shown in Figure 4(b) shows that AOHC-Ds has a wide mesopore size distribution $(2-50 \mathrm{~nm})$ with a peak of $3 \mathrm{~nm}$ and $8.75 \mathrm{~nm}$ for OHC-Ds. Another interesting result is that the biomass/citric acid mass ratio used for the formation of OHC-Ds $2: 0.1$ is lower than $8: 0.1$ reported by [59] or $5: 0.1$ by [39], which is excellent from an economic point of view for pilot scale use. On the other hand, the BET surface area of the same hydrochar after 
TABLE 3: Textural parameters from the $\mathrm{N}_{2}$ isotherm of AOHC-Ds and OHC-Ds.

\begin{tabular}{lccccc}
\hline Sample & $S_{\text {BET }}\left(\mathrm{m}^{2} / \mathrm{g}\right)$ & $V_{p}\left(\mathrm{~cm}^{3} / \mathrm{g}\right)$ & $V_{\text {micro }}\left(\mathrm{cm}^{3} / \mathrm{g}\right)$ & $V_{\text {meso }}\left(\mathrm{cm}^{3} / \mathrm{g}\right)$ & 0.12 \\
\hline OHC-Ds & 60.75 & 0.14 & 0.022 & $D_{p}\left(\mathrm{~nm}^{2}\right.$ \\
AOHC-Ds & 1251.5 & 0.736 & 0.310 & 0.426 \\
\hline
\end{tabular}

AOHC-Ds activation is $1251.5 \mathrm{~m}^{2} / \mathrm{g}$ (Figure 4(a)), 20 times more than that of OHC-Ds. In addition, the total pore volume increased from $0.14 \mathrm{~cm}^{3} / \mathrm{g}$ to $0.736 \mathrm{~cm}^{3} / \mathrm{g}$ with a considerable increase in the mesopore volume from $0.12 \mathrm{~cm}^{3} / \mathrm{g}$ to $0.426 \mathrm{~cm}^{3} / \mathrm{g}$, confirming the dominance of mesopores in the AOHC-Ds structure. In comparison, our results, which are slightly lower than those reported by [61] who have elaborated an activated carbon from the same precursor (with the conditions and textural characteristics relative to Table $7 \mathrm{~S}$ ), lead us to say that the preparation of a porous carbonaceous material from date seed by citric acid-catalyzed HTC followed by a chemical treatment proves to be more efficient than the application of HTC alone followed by a chemical or physical treatment.

3.3.3. FT-IR, XRD Analysis, and $p H_{P Z C}$. The FT-IR vibration spectra used to evaluate the effect of citric acid-catalyzed HTC on the surface functions of Ds, OHC-Ds, and AOHC-Ds are shown in Figure 5(a) and Table 8S. These spectra show eight zones suggesting the chemical structure and surface functional groups of these materials. First of all, the vibration spectrum of OHC-Ds is different from that of Ds, notably in the zone 1, a large bung at $3400 \mathrm{~cm}^{-1}$ which shows a medium narrowness attributed to the stretching hydroxyl $(-\mathrm{OH})$ group present in the structure of cellulose and hemicellulose. This finding is due to dehydration, decarboxylation reactions, and hydrolysis, which took place during the HTC reaction of date seeds. These differences can be explained by the effect of temperature, which several authors have already shown [61-63]. Then, the intensity of the bands was reduced in particular in the zone 4 to $1720 \mathrm{~cm}^{-1}$ at medium intensity, in the zone 7 to $1182 \mathrm{~cm}^{-1}$ at high intensity, and in the zone 8 to $1100 \mathrm{~cm}^{-1}$ at medium intensity, corresponding, respectively, to the elongation of the group $(\mathrm{C}=\mathrm{O})$ of the carboxylic acids, the elongation of the group $(\mathrm{C}-\mathrm{O})$ in the tertiary ester/alcohol (simple aliphatic), the elongation of the group (C-N), and the elongation of the group $(\mathrm{O}-\mathrm{H})$ of the alcohols [64]. These findings may be not only due to the temperature but also to the effect of citric acid. Recently, a study [39] showed that citric acid-catalyzed temperature increase in HTC to decrease the intensity of the $(-\mathrm{OH}),(-\mathrm{C}-\mathrm{H}),(\mathrm{C}-\mathrm{O})$, and $(\mathrm{C}-\mathrm{O}-\mathrm{H})$ grouping in the case of salacca peel. In this study, the decrease in the intensity of the vibrational bunches during citric acidcatalyzed HTC specifically for the date nucleus is due to the operating conditions (temperature and reaction time) and also favored by the contribution of citric acid to the dehydration, decarboxylation, and hydrolysis reactions. This decomposing nature of citric acid increases with the increasing amount added, consistent with the results found in van Krevelen diagram in Figure 3. On the other hand, the spectrum of AOHC-Ds shows a significant decrease relative to the hydrochar OHC-Ds in most bands except for the (-C$\mathrm{H})$ band at $2930 \mathrm{~cm}^{-1},(-\mathrm{C}-\mathrm{H})$ alkanes at $2860 \mathrm{~cm}^{-1},(-\mathrm{CH})$ methyl group at $1450 \mathrm{~cm}^{-1}$, and $(\mathrm{C}=\mathrm{C})$ unsaturated $\alpha$, $\beta$-ketone at $1620 \mathrm{~cm}^{-1}$ [65]. This is due to the chemical treatment with potassium hydroxide $(\mathrm{KOH})$ followed by activation at $600^{\circ} \mathrm{C}$. These functional groups are very important in the adsorption process, as they play the role of an active site capable of interacting with model molecules [66]. The effect of citric acid-catalyzed HTC on the crystal structure of OHC-Ds and AOHC-Ds was analyzed by X-ray diffraction (Figure 5(b)). As can be seen, the two XRD curves show that OHC-Ds and AOHC-Ds have an amorphous crystal structure. Obviously, the broad diffraction peak at $2 \theta=26^{\circ}$ is attributed to the (002) plane of the amorphous carbon comparable to graphite [67]. Indeed, the AOHC-Ds curve records another diffraction peak at $2 \theta=43^{\circ}$ less wide than the first one, attributed to the (100) plane, which indicates that the degree of graphitization increases with $\mathrm{KOH}$ treatment at $600^{\circ} \mathrm{C}$, which is in agreement with the studies of [68-70]. For the $\mathrm{pH}$ of AOHC-Ds at the zero-charge point shown in Figure 5(c), the curve $\mathrm{pH}_{\text {initial }}=f\left(\mathrm{pH}_{\text {final }}\right)$ intersection with the bisector reveals that the $\mathrm{pH}_{\mathrm{pzc}}$ of AOHC-Ds equals 6.75. This means that below $\mathrm{pH}_{\mathrm{pzc}}$, the surface of AOHC-Ds is positive, promoting adsorption between AOHC-Ds and negatively charged molecules and vice-versa [71].

\subsection{Adsorption Batch}

3.4.1. Effect of the Adsorption Parameter on the Removal Rate. Figure 6 shows the evolution of MB and MO removal rate as a function of $\mathrm{pH}$ in the range of $2-12$ with a $5 \mathrm{mg}$ AOHC-Ds mass, an initial concentration set at $50 \mathrm{mg} / \mathrm{L}$ for both dyes for 4 hours. As can be seen, the $R \%$ increases with increasing $\mathrm{pH}$ for $\mathrm{MB}$ and contrary to $\mathrm{MO}$. The high adsorbed amount for $\mathrm{MB}$ was obtained at $\mathrm{pH}=8$, and then, the amount remains unchanged. This can be explained by the competition between the ions $\left(\mathrm{H}^{+}\right)$in the acid region of $\mathrm{pH} \mathrm{2-7}$ and the MB molecules for the vacant pore's occupation on the surface of AOHC-Ds. In the basic $\mathrm{pH}$, the electrostatic force becomes important, which increases the $R(\%)$. However, the optimal rate $R(\%)$ for $\mathrm{MO}$ has been obtained at $\mathrm{pH}=5$. This is due to the negative charge carried by the MO competing with the ions $(-\mathrm{OH})$ in the basic region, which makes the $R(\%)$ less effective. In this context, we continued the adsorption tests by taking $\mathrm{pH}$ values of 8 and 5 for $\mathrm{MB}$ and $\mathrm{MO}$, respectively. By varying the mass of AOHC-Ds from $2.5 \mathrm{mg}$ to $25 \mathrm{mg}$ (Figure 6(a)), it can be seen that the percentage of elimination $R \%$ increases up to $96 \%$, corresponding to a mass of $0.01 \mathrm{~g}$ in the case of $\mathrm{MB}$ and then stabilizes despite the increase in the dose of AOHC-Ds. Similarly, for $\mathrm{MB}$, the same variation is observed, with a maximum elimination rate of $70 \%$ at $0.01 \mathrm{~g}$. Therefore, the 


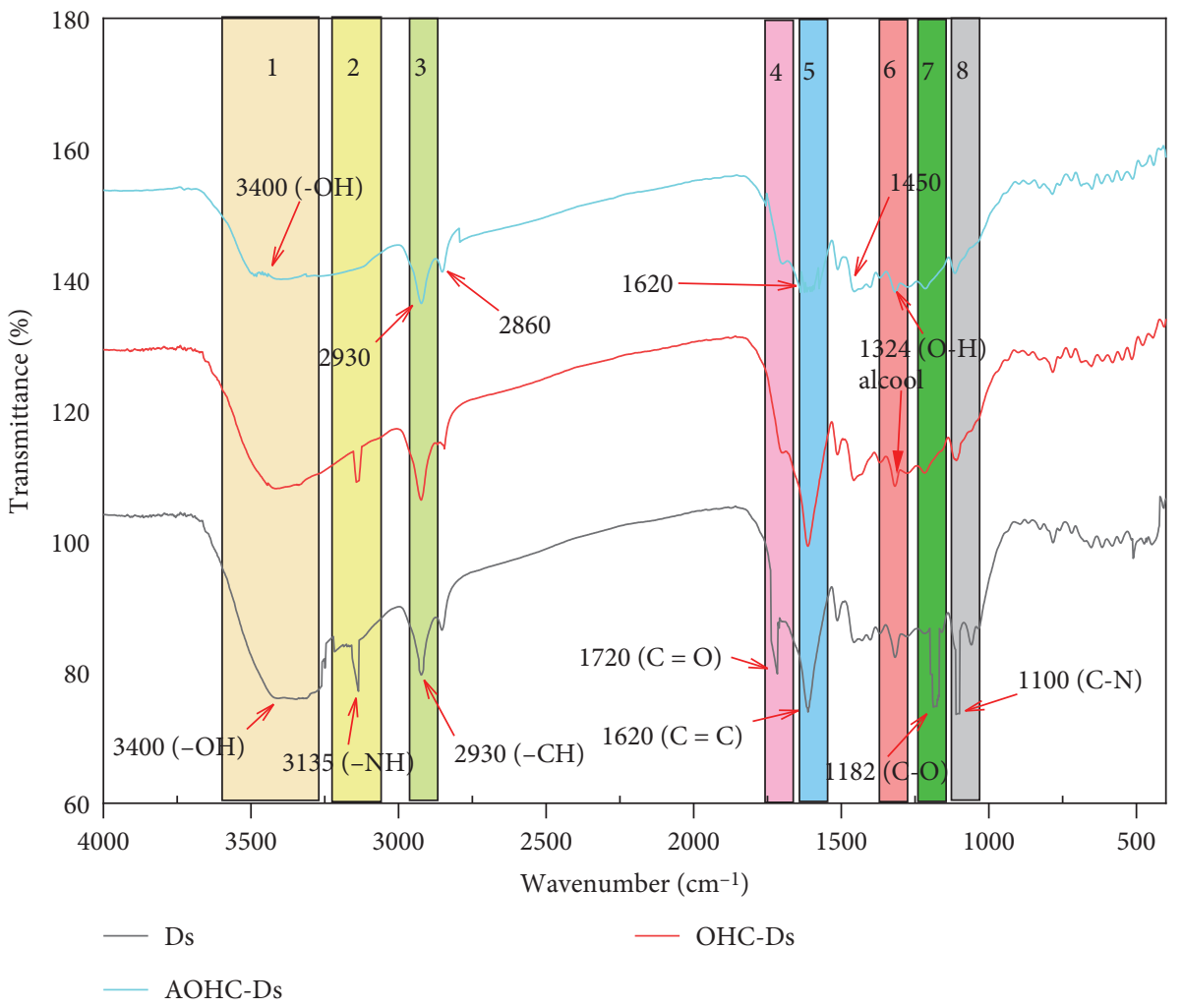

(a)

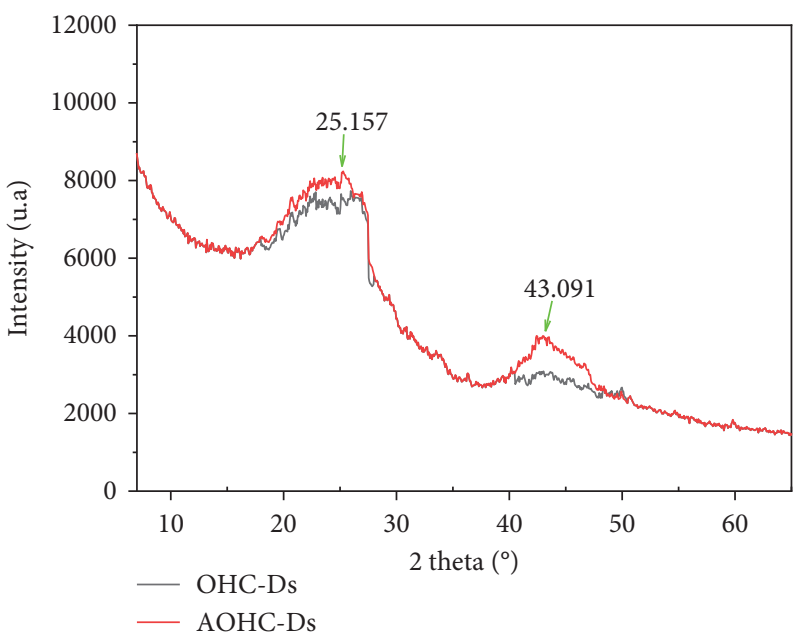

(b)

Figure 5: Continued. 


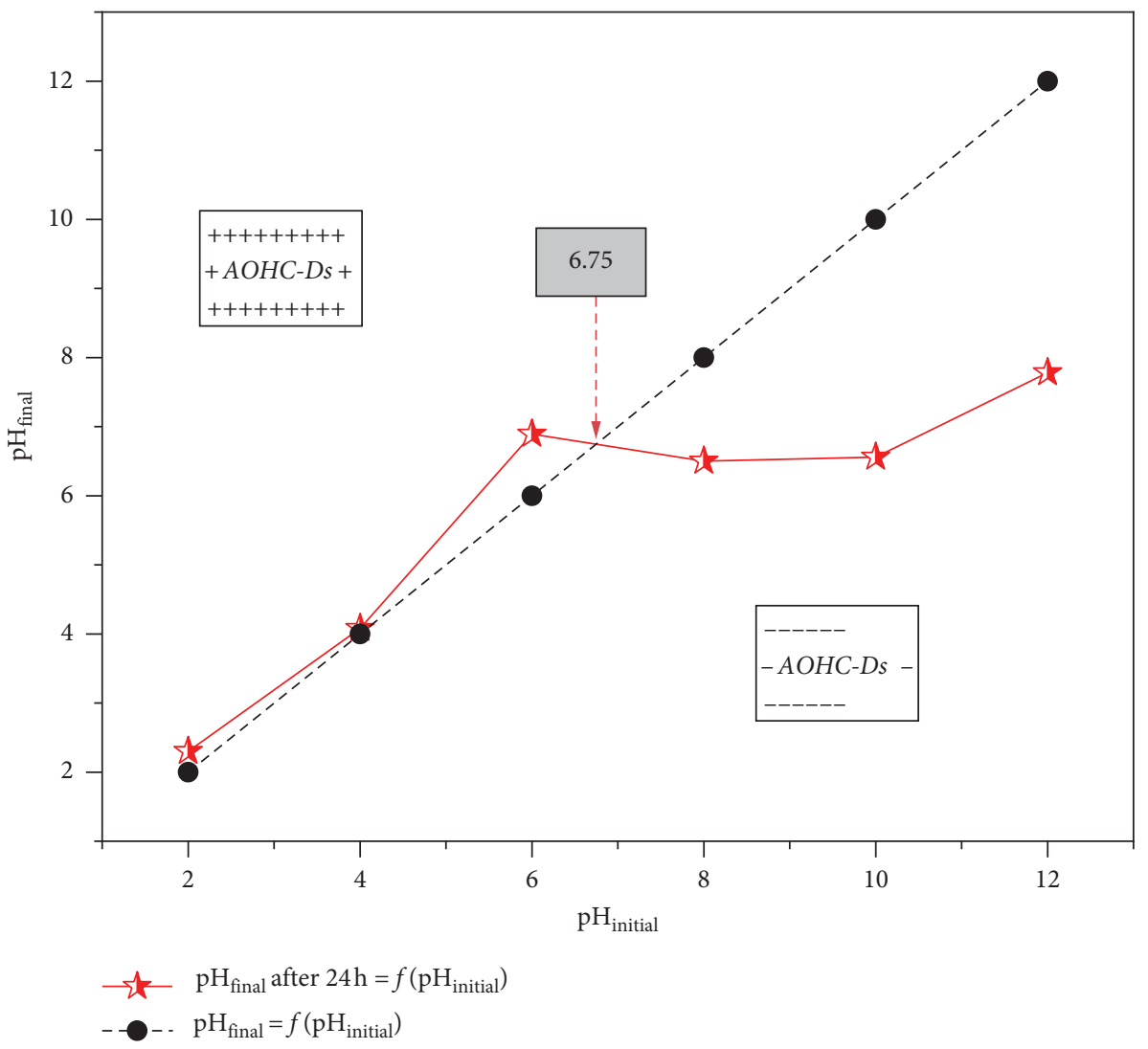

(c)

Figure 5: (a) FT-IR vibrational spectra of Ds, OHC-Ds, and AOHC-Ds. (b) XRD patterns of the OHC-Ds and AOHC-Ds. (c) Point of zero charge of the AOHC-Ds.

maximum dose for both dyes is taken as $0.01 \mathrm{~g}$. Several studies have reported that increasing the dose of adsorbent increases the elimination rate or the amount adsorbed $[36,72,73]$. Figure 6(c) shows that both dyes' removal rate increases to a maximum and then degrade. This is due to the availability of vacant pores in the structure of AOHC-Ds, which fills entirely at the concentration of $500 \mathrm{mg} / \mathrm{L}$ for $\mathrm{MB}$ and $300 \mathrm{mg} / \mathrm{L}$ for $\mathrm{MO}$. Indeed, our results are in perfect agreement with recent studies [74]. The results for the contact time shown in Figure 6(d) revealed that the removal rate of $\mathrm{MB}$ and $\mathrm{MO}$ increases rapidly and reaches its maximum in $10 \mathrm{~min}$ for $\mathrm{MB}$ and $25 \mathrm{~min}$ for $\mathrm{MO}$.

3.4.2. Adsorption Isotherm. The two most widely used models, Langmuir and Freundlich, for evaluating MB and MO adsorption behavior on AOHC-Ds were studied. The parameters of these two models are given in Table 4. First, based on the value of the $R^{2}$ coefficient, we find that the Langmuir model is closest to 1 for MB (0.83) and OM (0.89). On the one hand, this reveals that the Langmuir model better describes the adsorption process of $\mathrm{MB}$ and $\mathrm{MO}$ on $\mathrm{AOHC}-$ Ds than the Freundlich model. On the other hand, it reveals that the adsorption process probably occurs in a monolayer on the homogeneous surface of AOHC-Ds according to [75]. We also find that the coefficient $R^{2}$ for the two isotherms in
$\mathrm{MB}$ adsorption is very close, 0.83 for the Langmuir isotherm and 0.82 for Freundlich, indicating that both isotherms can describe the MB adsorption process. Next, the constant RL is between 0.012 and 0.29 for MB adsorption, and $0.0036-0.01$ for $\mathrm{MO}$ indicates that the adsorption process of the two dyes $\mathrm{MB}$ and $\mathrm{MO}$ is favorable on the AOHC-Ds. In addition, the maximum adsorption capacity $Q_{\max }$ calculated by the Langmuir model is $657.89\left(\mathrm{mg} \mathrm{g}^{-1}\right)$ for $\mathrm{MB}$ and 384.61 $\left(\mathrm{mg} \mathrm{g}^{-1}\right)$ for MO. This high value of $Q_{\max }$ is due to two things: the better affinity of AOHC-Ds towards methylene blue molecules, which is in agreement with the isotherms calculated parameters, notably the $K_{\mathrm{L}}$ value, which is less than 1 . Then, there is the high specific surface area $\left(1251.5 \mathrm{~m}^{2} / \mathrm{g}\right)$ and the pore volume $\left(0.736 \mathrm{~cm}^{3} / \mathrm{g}\right)$ obtained with AOHC-Ds, which play a crucial role in the adsorption process [7]. From these results, the possible adsorption mechanisms are an electrostatic attraction, interactions $\pi-\pi$ or $n-\pi$, in the case of $\mathrm{MB}$ adsorption according to [76] and the formation of the hydrogen bond and the hydrophobic interaction in the case of methyl orange [77].

\section{Comparison with Previous Work}

Table 7S shows the maximum adsorption capacities $\left(Q_{\max }\right)$ of carbonaceous materials prepared from other precursors, agricultural by-products, and industrial wastes. It is quite 

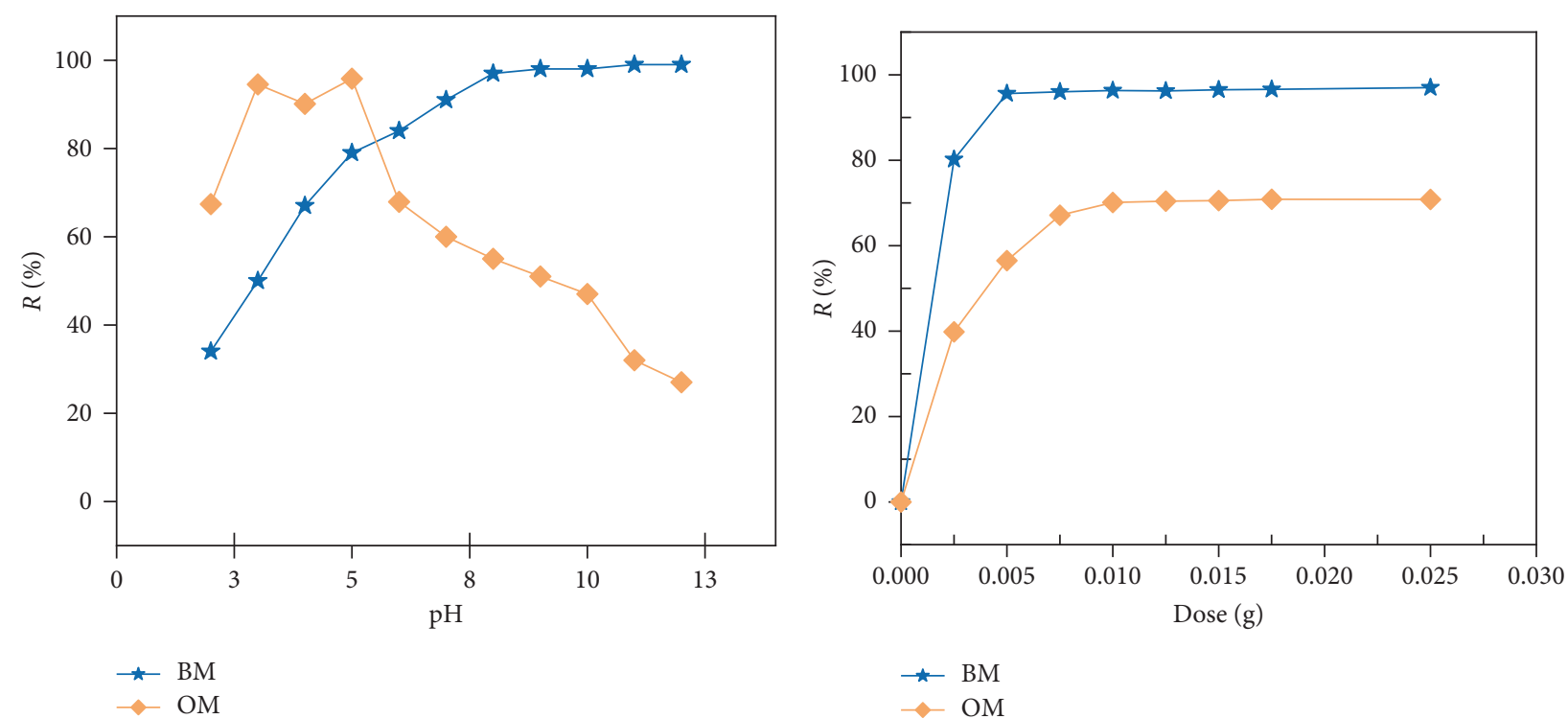

(a)
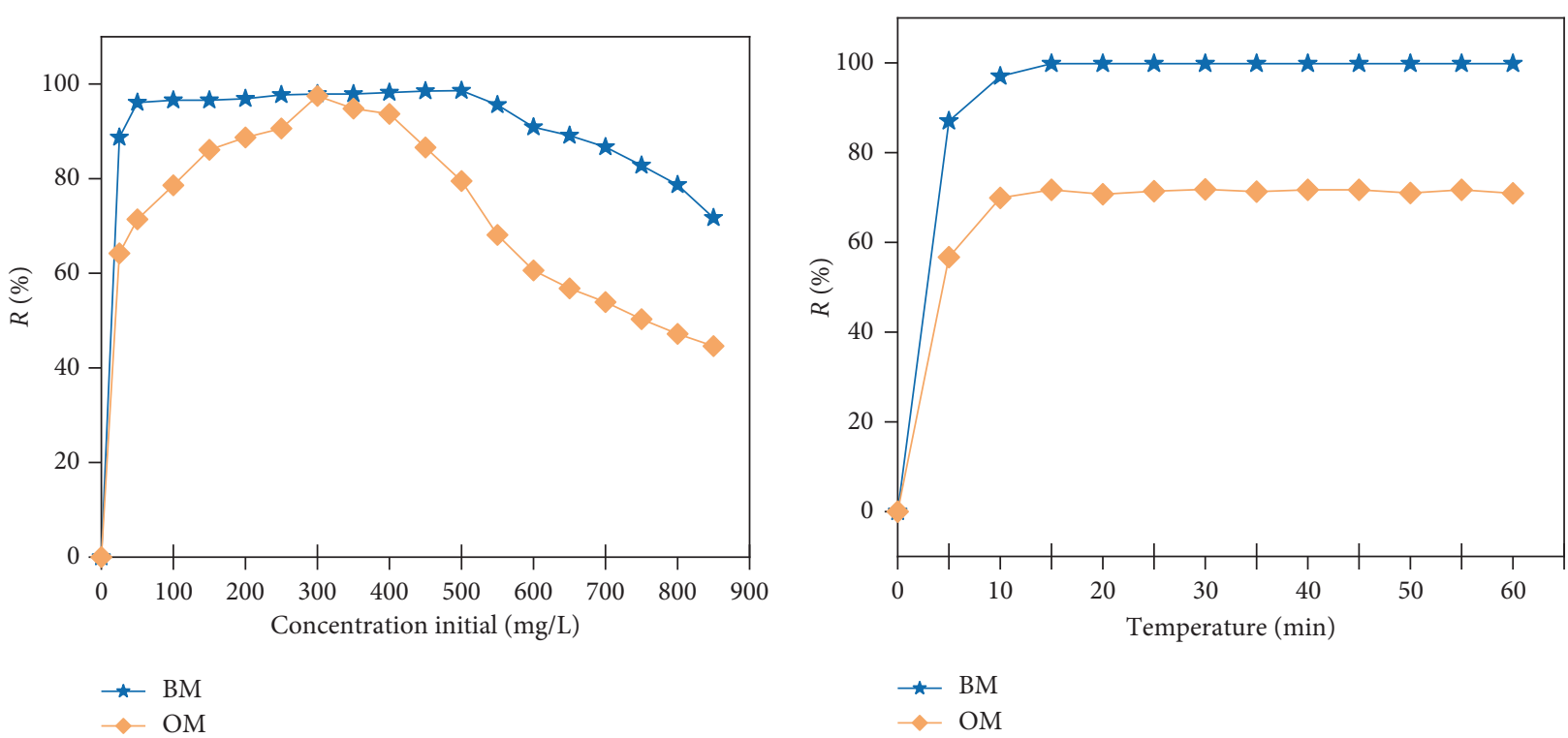

(c)

(d)

Figure 6: (a) Effect of $\mathrm{pH}\left(m=0.005 \mathrm{~g}, V=100 \mathrm{~mL}, t=4 \mathrm{~h}, C_{0}=50 \mathrm{mg} / \mathrm{L}\right.$, and $\left.T=25^{\circ} \mathrm{C}\right)$. (b) Effect of the AOHC-Ds dose $(\mathrm{MB}$ : $\mathrm{pH}=5$, $V=100 \mathrm{~mL}, t=4 \mathrm{~h}, C_{0}=50 \mathrm{mg} / \mathrm{L}, T=25^{\circ} \mathrm{C} \mathrm{MO}: \mathrm{pH}=5, V=100 \mathrm{~mL}, t=4 \mathrm{~h}, C_{0}=50 \mathrm{mg} / \mathrm{L}$, and $T=25^{\circ} \mathrm{C}$ ). (c) Effect of the initial concentration (MB: $\mathrm{pH}=8, V=100 \mathrm{~mL}, t=4 \mathrm{~h}, T=25^{\circ} \mathrm{C}, m=0.01 \mathrm{~g} \mathrm{MO}: \mathrm{pH}=5, V=100 \mathrm{~mL}, t=4 \mathrm{~h}, T=25^{\circ} \mathrm{C}$, and $m=0.01 \mathrm{~g}$ ). (d) Effect of contact time (MB: $\mathrm{pH}=8, V=100 \mathrm{~mL}, C_{0}=50 \mathrm{mg} / \mathrm{L}, T=25^{\circ} \mathrm{C}, m=0.01 \mathrm{~g} \mathrm{MO}: \mathrm{pH}=5, V=100 \mathrm{~mL}, C_{0}=50 \mathrm{mg} / \mathrm{L}, T=25^{\circ} \mathrm{C}$, and $m=0.01 \mathrm{~g}$ ) on the rate of removal of $\mathrm{MB}$ and $\mathrm{MO}$.

TABLE 4: Parameter of the adsorption isotherms for $\mathrm{MB}$ and $\mathrm{OM}$ at $25^{\circ} \mathrm{C}$.

\begin{tabular}{lccc}
\hline Isothermal model & Parameters & BM & OM \\
\hline \multirow{4}{*}{ Langmuir } & $Q_{\mathrm{m}}\left(\mathrm{mgg}^{-1}\right)$ & 657.89 & 384.62 \\
& $K_{\mathrm{L}}\left(\mathrm{L} \mathrm{mg}^{-1}\right)$ & 0.098 & 0.329 \\
& $R^{2}$ & 0.83 & 0.89 \\
Freundlich & $R_{\mathrm{L}}$ range & $0.012-0.29$ & $0.0036-0.0108$ \\
& $\mathrm{~K}^{\mathrm{F}}(\mathrm{mg} / \mathrm{g}(1 / \mathrm{mg}))$ & 407.320 & 265.49606 \\
& $1 / n_{F}$ & 0.0813 & 0.0587 \\
\hline
\end{tabular}


clear that the synthesis condition plays a significant role in the formation of a porous material with moderate and controlled characteristics such as the specific surface area. Indeed, by comparing the adsorption capacities by the synthesis method proposed in this study with the one mentioned in Table 7S, we can say that the coupling of hydrothermal carbonization catalyzed by citric acid is efficient and less expensive for two reasons. First, the precursor used is an agricultural by-product considered waste, which means that its cost is lower than that used for the production of activated carbon such as wood. Second, the synthesized material AOHC-Ds has shown comparable efficiency compared to other raw materials in removing methylene blue and methyl orange. All these properties make our material very promising for the remediation of dye-contaminated water.

\section{Conclusion}

The application of citric acid-catalyzed hydrothermal carbonization in this study using the surface response methodology demonstrated its effectiveness in converting the date seeds to hydrochar. Under the conditions $X_{A}=200^{\circ} \mathrm{C}$, $X_{B}=120 \mathrm{~min}$, and $X_{C}=20 \mathrm{mg}$, CHTC produced an optimized carbon-rich hydrochar. The activation of the optimized hydrochar gave a mesoporous material with interesting characteristics comparable to activated carbon. Characterizations by XRD, FTIR, and BET techniques show that our material is amorphous with a large specific surface area of $1251.5 \mathrm{~m}^{2} / \mathrm{g}$ and contains interesting functions on its surface, which allow it to be a good candidate in the field of adsorption. The methylene blue and methyl orange adsorption tests performed on AOHC-Ds showed a good adsorbent-adsorbate affinity represented by the maximum adsorption capacity of $657.89 \mathrm{mg} \mathrm{g}^{-1}$ for MB adsorption and $384.61 \mathrm{mg} \mathrm{g}^{-1}$ for MO adsorption. CHTC coupling and chemical activation followed by pyrolysis proposed in this study promise to produce porous carbon-rich materials derived from biomass and lignocellulosic wastes.

\section{Data Availability}

The data used to support the findings of this study are included within the article and in Supplementary Materials and are also available from the corresponding author upon request.

\section{Conflicts of Interest}

The authors declare that they have no conflicts of interest.

\section{Supplementary Materials}

Additional data related to this are included in the Supporting Information file. Figure 1S. Geometrical location of the experimental points of the CCD design for $k=3$ factors and $\alpha=1.68$. Figure $2 \mathrm{~S}$. (a) $2 \mathrm{D}$ plot of the $Y_{\mathrm{m}}(\%)$ and (b) response surface of the $Y_{\mathrm{m}}(\%)$ with a fixed catalyst dose (XC $=17.5 \mathrm{mg}$ ). Figure 3S. (a) $2 \mathrm{D}$ plot of the $\mathrm{C}_{\mathrm{RR}}(\%)$ and (b) response surface of the $\mathrm{C}_{\mathrm{RR}}(\%)$ with a fixed reaction time
( $X_{B}=90 \mathrm{~min}$ ). Figure 4S. (a) Bar histogram and (b) graphical representation of the desirability function for the optimal solution $(D=0.887)$. Table $1 S$. Experimental matrix of the CCD design. Table $2 S$. ANOVA analysis for the quadratic mass yield model. Table 3S. ANOVA analysis for the quadratic carbon recovery rate model. Table 4 S. Optimization constraints. Table 5S. Elemental analysis, atomic ratios, and higher heating value HHV of hydrochars produced using the CCD design. Table 6S. Equations used in the calculation of $\mathrm{MO}$ and $\mathrm{MB}$ adsorption on AOHC-Ds. Table 7S. Comparison of adsorption performance of AOHC-Ds with other works. Table 8S. Group functional with their frequency wavenumber extracted from the FTIR analysis. (Supplementary Materials)

\section{References}

[1] International Energy Agency, World Energy Balances, 1960-2018, International Energy Agency, Paris, France, 2020. https://www.iea.org/reports/world-energy-balances-overview.

[2] M. Brower, E. M. Galán, L. Junfeng et al., REN 21 Steering Committee Industry Associations Rainer Hinrichs-Rahlwes European Renewable Energies Federation (EREF) International Organisations NGOS Ibrahim Togola Mali Folkecenter/ Citizens United for Renewable Energy and Sustainability (CURES) Irene G, 2014, http://www.ren21.net/Portals/0/ documents/Resources/GSR/2014/GSR2014_full\%20report_lo w\%20res.pdf.

[3] H. Ritchie and M. Roser, Water Use and Stress Freshwater Use Global Freshwater Use. Our World in Data, 2018, https:// ourworldindata.org/water-use-stress.

[4] T. Deblonde, C. Cossu-Leguille, and P. Hartemann, "Emerging pollutants in wastewater: a review of the literature," International Journal of Hygiene and Environmental Health, vol. 214, no. 6, pp. 442-448, 2011.

[5] W. Burnside, "Wastewater disease indicators," Nature Sustainability, vol. 1, no. 5, p. 211, 2018.

[6] S. K. Fanourakis, J. Peña-Bahamonde, P. C. Bandara, and D. F. Rodrigues, "Nano-based adsorbent and photocatalyst use for pharmaceutical contaminant removal during indirect potable water reuse," NPJ Clean Water, vol. 3, no. 1, p. 1, 2020.

[7] N. C. Corda and M. S. Kini, "A review on adsorption of cationic dyes using activated carbon," MATEC Web of Conferences, vol. 144, pp. 1-16, 2018.

[8] B. Khiari, M. Jeguirim, L. Limousy, and S. Bennici, "Biomass derived chars for energy applications," Renewable and Sustainable Energy Reviews, vol. 108, pp. 253-273, 2019.

[9] M. Sivachidambaram, J. J. Vijaya, L. J. Kennedy et al., "Preparation and characterization of activated carbon derived from the: borassus flabellifer flower as an electrode material for supercapacitor applications," New Journal of Chemistry, vol. 41, no. 10, pp. 3939-3949, 2017.

[10] I. Izanzar, M. Dahbi, M. Kiso, S. Doubaji, S. Komaba, and I. Saadoune, "Hard carbons issued from date palm as efficient anode materials for sodium-ion batteries," Carbon, vol. 137, pp. 165-173, 2018.

[11] Titirici, M. Magdalena, and M. Antonietti, "Chemistry and materials options of sustainable carbon materials made by hydrothermal carbonization," Chemical Society Reviews, vol. 39, no. 1, pp. 103-116, 2010.

[12] E. F. Abouraïcha, F. Jaiti, and I. El. Hadrami, "Problématique de la phœniciculture au Maroc," in Biotechnologies du Palmier Dattier, pp. 45-54, 2017, IRD Éditions. 
[13] K. A. S. Diab and E. I. Aboul-Ela, "In vivo comparative studies on antigenotoxicity of date palm (Phoenix dactylifera 1.) pits extract against DNA damage induced by N-Nitroso-Nmethylurea in mice," Toxicology International, vol. 19, no. 3, pp. 279-286, 2012.

[14] N. M. Haimour and S. Emeish, "Utilization of date stones for production of activated carbon using phosphoric acid," vol. 26, pp. 651-660, 2006.

[15] M. J. Ahmed, "Preparation of activated carbons from date (Phoenix dactylifera L.) palm stones and application for wastewater treatments: review," Process Safety and Environmental Protection, vol. 102, pp. 168-182, 2016.

[16] M. A. Islam, M. J. Ahmed, W. A. Khanday, M. Asif, and B. H. Hameed, "Mesoporous activated coconut shell-derived hydrochar prepared via hydrothermal carbonization- $\mathrm{NaOH}$ activation for methylene blue adsorption," Journal of Environmental Management, vol. 203, pp. 237-244, 2017.

[17] A. Jain, R. Balasubramanian, and M. P. Srinivasan, "Hydrothermal conversion of biomass waste to activated carbon with high porosity: a review," Chemical Engineering Journal, vol. 283, pp. 789-805, 2016.

[18] F. Shen, Y. Wang, L. Li, K. Zhang, R. L. Smith, and X. Qi, "Porous carbonaceous materials from hydrothermal carbonization and $\mathrm{KOH}$ activation of corn stover for highly efficient $\mathrm{CO}_{2}$ capture," Chemical Engineering Communications, vol. 205, no. 4, pp. 423-431, 2018.

[19] K. sung Wang, M. C. Wei, T. H. Peng et al., “Treatment and toxicity evaluation of methylene blue using electrochemical oxidation, fly ash adsorption and combined electrochemical oxidation-fly ash adsorption," Journal of Environmental Management, vol. 91, no. 8, pp. 1778-1784, 2010.

[20] A. L. Tasca, M. Puccini, E. Stefanelli, R. Gori, A. M. R. Galletti, and S. Vitolo, "Investigating the activation of hydrochar from sewage sludge for the removal of terbuthylazine from aqueous solutions," Journal of Material Cycles and Waste Management, vol. 22, no. 5, pp. 1539-1551, 2020.

[21] M. Mäkelä, "Experimental design and response surface methodology in energy applications: a tutorial review," Energy Conversion and Management, vol. 151, pp. 630-640, 2017.

[22] Z. Anfar, H. Ait Ahsaine, M. Zbair et al., "Recent trends on numerical investigations of response surface methodology for pollutants adsorption onto activated carbon materials: a review," Critical Reviews in Environmental Science and Technology, vol. 50, no. 10, pp. 1-42, 2019.

[23] I. M. Yusri, A. P. P. Abdul Majeed, R. Mamat, M. F. Ghazali, O. I. Awad, and W. H. Azmi, "A review on the application of response surface method and artificial neural network in engine performance and exhaust emissions characteristics in alternative fuel," Renewable and Sustainable Energy Reviews, vol. 90, pp. 665-686, 2018.

[24] E. Hazir and T. Ozcan, "Response surface methodology integrated with desirability function and genetic algorithm approach for the optimization of CNC machining parameters," Arabian Journal for Science and Engineering, vol. 44, no. 3, pp. 2795-2809, 2019.

[25] M. J. Anderson and P. J. Whitcomb, Optimizing Formulation Performance_With_Desirability Functions, Canadian Institute of Metallurgy, Montreal, Canada, 1993.

[26] D. R. Nhuchhen and M. T. Afzal, "HHV predicting correlations for torrefied biomass using proximate and ultimate analyses," Bioengineering, vol. 4, no. 1, p. 7, 2017.

[27] C. Nobre, C. Vilarinho, O. Alves, B. Mendes, and M. Gonçalves, "Upgrading of refuse derived fuel through torrefaction and carbonization: evaluation of RDF char fuel properties," Energy, vol. 181, pp. 66-76, 2019.

[28] R. J. Stirling, C. E. Snape, and W. Meredith, "The impact of hydrothermal carbonisation on the char reactivity of biomass," Fuel Processing Technology, vol. 177, pp. 152-158, 2018.

[29] E. Danso-boateng, Biomass Hydrothermal Carbonisation for Sustainable Engineering, Loughborough University, Loughborough, UK, 2015, https://dspace.lboro.ac.uk/2134/19043.

[30] D. Gupta, S. M. Mahajani, and A. Garg, "Effect of hydrothermal carbonization as pretreatment on energy recovery from food and paper wastes," Bioresource Technology, vol. 285, Article ID 121329, 2019.

[31] O. O. D. Afolabi, M. Sohail, and Y. L. Cheng, "Optimisation and characterisation of hydrochar production from spent coffee grounds by hydrothermal carbonisation," Renewable Energy, vol. 147, pp. 1380-1391, 2020.

[32] M. Volpe, D. Wüst, F. Merzari et al., "One stage olive mill waste streams valorisation via hydrothermal carbonisation," Waste Management, vol. 80, pp. 224-234, 2018.

[33] ASTM D6556-19, Standard Test Method for Carbon Black-Total and External Surface Area by Nitrogen Adsorption, ASTM International, West Conshohocken, PA, USA, 2019, https://www. astm.org/database.cart/historical/D6556-01.htm.

[34] E. P. Barrett, L. G. Joyner, and P. P. Halenda, "The determination of pore volume and area distributions in porous substances. I. Computations from nitrogen isotherms," Journal of the American Chemical Society, vol. 73, no. 1, pp. 373-380, 1951.

[35] P. Klobes, K. Meyer, and R. G. Munro, "Porosity and specific surface area measurements for solid materials," Materials Science, vol. 960, p. 79, 2006.

[36] F. Mbarki, A. Kesraoui, M. Seffen, and P. Ayrault, "Kinetic, thermodynamic, and adsorption behavior of cationic and anionic dyes onto corn stigmata: nonlinear and stochastic analyses," Water, Air, and Soil Pollution, vol. 229, no. 3, 2018.

[37] A. Xie, J. Dai, X. Chen et al., "Hierarchical porous carbon materials derived from a waste paper towel with ultrafast and ultrahigh performance for adsorption of tetracycline," RSC Advances, vol. 6, no. 77, pp. 72985-72998, 2016.

[38] X. Lu, P. J. Pellechia, J. R. V. Flora, and N. D. Berge, "Influence of reaction time and temperature on product formation and characteristics associated with the hydrothermal carbonization of cellulose," Bioresource Technology, vol. 138, pp. 180190, 2013.

[39] R. F. Susanti, A. A. Arie, H. Kristianto, M. Erico, G. Kevin, and H. Devianto, "Activated carbon from citric acid catalyzed hydrothermal carbonization and chemical activation of salacca peel as potential electrode for lithium ion capacitor's cathode," Ionics, vol. 25, no. 8, pp. 3915-3925, 2019.

[40] M. M. Titirici, A. Thomas, S. H. Yu, J. O. Müller, and M. Antonietti, "A direct synthesis of mesoporous carbons with bicontinuous pore morphology from crude plant material by hydrothermal carbonization," Chemistry of Materials, vol. 19, no. 17, pp. 4205-4212, 2007.

[41] B. B. Hu, K. Wang, L. Wu, S. H. Yu, M. Antonietti, and M. M. Titirici, "Engineering carbon materials from the hydrothermal carbonization process of biomass," Advanced Materials, vol. 22, no. 7, pp. 813-828, 2010.

[42] M. Sevilla and A. B. Fuertes, "The production of carbon materials by hydrothermal carbonization of cellulose," Carbon, vol. 47, no. 9, pp. 2281-2289, 2009.

[43] G. Bensidhom, A. Ben Hassen-Trabelsi, K. Alper, M. Sghairoun, K. Zaafouri, and I. Trabelsi, "Pyrolysis of date palm waste in a fixed-bed reactor: characterization of 
pyrolytic products," Bioresource Technology, vol. 247, pp. 363-369, 2018.

[44] M. L. Sekirifa, M. Hadj-Mahammed, S. Pallier, L. Baameur, D. Richard, and A. H. Al-Dujaili, "Preparation and characterization of an activated carbon from a date stones variety by physical activation with carbon dioxide," Journal of Analytical and Applied Pyrolysis, vol. 99, pp. 155-160, 2013.

[45] J. Mumme, L. Eckervogt, J. Pielert, M. Diakité, F. Rupp, and J. Kern, "Hydrothermal carbonization of anaerobically digested maize silage," Bioresource Technology, vol. 102, no. 19, pp. 9255-9260, 2011.

[46] R. F. Faradilla, L. Lucia, and M. Hakovirta, "Remarkable physical and thermal properties of hydrothermal carbonized nanoscale cellulose observed from citric acid catalysis and acetone rinsing," Nanomaterials, vol. 10, no. 6, 2020.

[47] X. Lu, J. R. V. Flora, and N. D. Berge, "Influence of process water quality on hydrothermal carbonization of cellulose," Bioresource Technology, vol. 154, pp. 229-239, 2014.

[48] Z. Yao, X. Ma, and Y. Lin, "Effects of hydrothermal treatment temperature and residence time on characteristics and combustion behaviors of green waste," Applied Thermal Engineering, vol. 104, pp. 678-686, 2016.

[49] Y. Zhao, W. Li, X. Zhao, D. P. Wang, and S. X. Liu, "Carbon spheres obtained via citric acid catalysed hydrothermal carbonisation of cellulose," Materials Research Innovations, vol. 17, no. 7, pp. 546-551, 2013.

[50] H. Xiao, Y. Guo, X. Liang, and C. Qi, "One-step synthesis of novel biacidic carbon via hydrothermal carbonization," Journal of Solid State Chemistry, vol. 183, no. 7, pp. 1721-1725, 2010.

[51] A. Kumar and H. M. Jena, "Preparation and characterization of high surface area activated carbon from Fox nut (Euryale ferox) shell by chemical activation with $\mathrm{H}_{3} \mathrm{PO}_{4}$," Results in Physics, vol. 6, pp. 651-658, 2016.

[52] S. Zhang, K. Sheng, W. Yan et al., "Bamboo derived hydrochar microspheres fabricated by acid-assisted hydrothermal carbonization," Chemosphere, vol. 263, Article ID 128093, 2021.

[53] D. W. V. Krevelen, Coal, Elsevier, Amsterdam, Netherlands, 1993, https://www.elsevier.com/books/coal/van-krevelen/ 978-0-444-89586-8, 3rd edition.

[54] D. Basso, E. Weiss-Hortala, F. Patuzzi, M. Baratieri, and L. Fiori, "Deep analysis on the behavior of Grape marc constituents during hydrothermal carbonization," Energies, vol. 11, no. 6, p. 1379, 2018.

[55] A. Ghaziaskar, G. A. McRae, A. MacKintosh, and O. D. Basu, "Catalyzed hydrothermal carbonization with process liquid recycling," Energy and Fuels, vol. 33, no. 2, pp. 1167-1174, 2019.

[56] M. A. Rather, N. S. Khan, and R. Gupta, "Catalytic hydrothermal carbonization of invasive macrophyte Hornwort (Ceratophyllum demersum) for production of hydrochar: a potential biofuel," International Journal of Environmental Science and Technology, vol. 14, no. 6, pp. 1243-1252, 2017.

[57] K. A. Cychosz, R. Guillet-Nicolas, J. García-Martínez, and M. Thommes, "Recent advances in the textural characterization of hierarchically structured nanoporous materials," Chemical Society Reviews, vol. 46, no. 2, pp. 389-414, 2017.

[58] K. S. W. Sing, D. H. Everett, R. A. W. Haul et al., "Reporting physisorption data for gas/solid systems with special reference to the determination of surface area and porosity," Pure and Applied Chemistry, vol. 57, no. 4, pp. 603-619, 1985.

[59] E. Unur, S. Brutti, S. Panero, and B. Scrosati, "Nanoporous carbons from hydrothermally treated biomass as anode materials for lithium ion batteries," Microporous and Mesoporous Materials, vol. 174, pp. 25-33, 2013.

[60] N. Saha, M. Volpe, L. Fiori, R. Volpe, A. Messineo, and M. T. Reza, "Cationic dye adsorption on hydrochars of winery and citrus juice industries residues: performance, mechanism, and thermodynamics," Energies, vol. 13, no. 18, p. 4686, 2020.

[61] A. Islam, I. A. W. Tan, A. Benhouria, M. Asif, and B. H. Hameed, "Mesoporous and adsorptive properties of palm date seed activated carbon prepared via sequential hydrothermal carbonization and sodium hydroxide activation School of Chemical Engineering, Engineering Campus, Foretsry and Wood Technology Discipline, Khul," Chemical Engineering Journal, 2015.

[62] A. Jain, C. Xu, S. Jayaraman, R. Balasubramanian, J. Y. Lee, and M. P. Srinivasan, "Mesoporous activated carbons with enhanced porosity by optimal hydrothermal pre-treatment of biomass for supercapacitor applications," Microporous and Mesoporous Materials, vol. 218, pp. 55-61, 2015.

[63] Y. Zhu, Y. Si, X. Wang et al., "Characterization of hydrochar pellets from hydrothermal carbonization of agricultural residues," Energy and Fuels, vol. 32, no. 11, pp. 11538-11546, 2018.

[64] P. J. Larkin, Infrared and Raman Spectroscopy: Principles and Spectral Interpretation, Elsevier, Amsterdam, Netherlands, 2017, https://books.google.co.ma/books? id=KPyV1DRMRbwC\&redir_esc $=$ y.

[65] S. Aldrich, IR Spectrum Table \& Chart|Sigma-Aldrich, IR Spectrum Table \& Chart, Merck KGaA, Darmstadt, Germany, 2018, https://www.sigmaaldrich.com/technical-documents/ articles/biology/ir-spectrum-table.html.

[66] S. De Gisi, G. Lofrano, M. Grassi, and M. Notarnicola, "Characteristics and adsorption capacities of low-cost sorbents for wastewater treatment: a review," Sustainable Materials and Technologies, vol. 9, pp. 10-40, 2016.

[67] B. S. Girgis, Y. M. Temerk, M. M. Gadelrab, and I. D. Abdullah, "X-ray diffraction patterns of activated carbons prepared under various conditions," Carbon Letters, vol. 8, no. 2, pp. 95-100, 2007.

[68] F. G. F. de Paula, I. Campello-Gómez, P. F. R. Ortega, F. Rodríguez-Reinoso, M. Martínez-Escandell, and J. Silvestre-Albero, "Structural flexibility in activated carbon materials prepared under harsh activation conditions," $M a$ terials, vol. 12, no. 12, 2019.

[69] Y. Gong, H. Wang, Z. Wei, L. Xie, and Y. Wang, "An efficient way to introduce hierarchical structure into biomass-based hydrothermal carbonaceous materials," ACS Sustainable Chemistry and Engineering, vol. 2, no. 10, pp. 2435-2441, 2014.

[70] M. Zbair, H. Ait Ahsaine, and Z. Anfar, "Porous carbon by microwave assisted pyrolysis: an effective and low-cost adsorbent for sulfamethoxazole adsorption and optimization using response surface methodology," Journal of Cleaner Production, vol. 202, pp. 571-581, 2018.

[71] S. Madduri, I. Elsayed, and E. B. Hassan, "Novel oxone treated hydrochar for the removal of $\mathrm{Pb}(\mathrm{II})$ and methylene blue (MB) dye from aqueous solutions," Chemosphere, vol. 260, Article ID 127683, 2020.

[72] L. Luo, X. Wu, Z. Li et al., "Synthesis of activated carbon from biowaste of fir bark for methylene blue removal," Royal Society Open Science, vol. 6, no. 9, Article ID 190523, 2019.

[73] H. Yang, L. Weijun, W. Weiqing, F. Qiming, and L. Jing, "Synthesis of a carbon@Rectorite nanocomposite adsorbent by a hydrothermal carbonization process and their application in the removal of methylene blue and neutral red from 
aqueous solutions," Desalination and Water Treatment, vol. 57, no. 29, pp. 13573-13585, 2016.

[74] S. Jellali, M. Labaki, A. A. Azzaz, H. Akrout, L. Limousy, and M. Jeguirim, "7 - biomass-derived chars used as adsorbents for liquid and gaseous effluents treatment," in Char and Carbon from Biomass, Elsevier, Amsterdam, Netherlands, 2019.

[75] M. A. Al-Ghouti and R. S. Al-Absi, "Mechanistic understanding of the adsorption and thermodynamic aspects of cationic methylene blue dye onto cellulosic olive stones biomass from wastewater," Scientific Reports, vol. 10, no. 1, Article ID 15928, 2020.

[76] M. Zbair, K. Ainassaari, Z. El Assal et al., "Steam activation of waste biomass: highly microporous carbon, optimization of bisphenol A, and diuron adsorption by response surface methodology," Environmental Science and Pollution Research, vol. 25, no. 35, pp. 35657-35671, 2018.

[77] S. Khan, A. Achazhiyath Edathil, and F. Banat, "Sustainable synthesis of graphene-based adsorbent using date syrup," Scientific Reports, vol. 9, no. 1, Article ID 18106, 2019. 